\title{
Electronic kinetics of molecular nitrogen and molecular oxygen in high-latitude lower thermosphere and mesosphere
}

\author{
A. S. Kirillov \\ Polar Geophysical Institute of the Kola Science Centre RAS, Apatity, 184209, Russia \\ Received: 7 October 2008 - Revised: 13 January 2010 - Accepted: 14 January 2010 - Published: 20 January 2010
}

\begin{abstract}
Total quenching rate coefficients of Herzberg states of molecular oxygen and three triplet states of molecular nitrogen in the collisions with $\mathrm{O}_{2}$ and $\mathrm{N}_{2}$ molecules are calculated on the basis of quantum-chemical approximations. The calculated rate coefficients of electronic quenching of $\mathrm{O}_{2}^{*}$ and $\mathrm{N}_{2}^{*}$ molecules show a good agreement with available experimental data. An influence of collisional processes on vibrational populations of electronically excited $\mathrm{N}_{2}$ and $\mathrm{O}_{2}$ molecules is studied for the altitudes of high-latitude lower thermosphere and mesosphere during auroral electron precipitation. It is indicated that molecular collisions of metastable nitrogen $\mathrm{N}_{2}\left(\mathrm{~A}^{3} \Sigma_{u}^{+}\right)$with $\mathrm{O}_{2}$ molecules are principal mechanism in electronic excitation of both Herzberg states $c^{1} \Sigma_{u}^{-}, \mathrm{A}^{\prime 3} \Delta_{u}, \mathrm{~A}^{3} \Sigma_{u}^{+}$and high vibrational levels of singlet states $a^{1} \Delta_{g}$ and $b^{1} \Sigma_{g}^{+}$of molecular oxygen $\mathrm{O}_{2}$ at these altitudes.
\end{abstract}

Keywords. Atmospheric composition and structure (Airglow and aurora) - Ionosphere (Active experiments; Auroral ionosphere)

\section{Introduction}

The study of electronic kinetics of atmospheric components in the region of high-latitude lower thermosphere and mesosphere $(80-100 \mathrm{~km})$ is required for a few reasons. Firstly, high-energetic auroral electrons penetrate to these altitudes causing the type B aurora (Gattinger and Vallance Jones, 1979; Gattinger et al., 1985). Benesch (1981, 1983), Morrill and Benesch (1996), Kirillov (2008a) have shown that vibrational populations of the triplet manifolds of molecular nitrogen are strongly affected by collision processes at the altitudes. This dependence of vibrational populations of

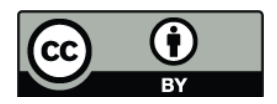

Correspondence to: A. S. Kirillov (kirillov@pgia.ru) electronically excited $\mathrm{N}_{2}$ on the rates of collisional processes causes a redistribution of First Positive Group (1PG) relative intensities with the increase in the density of the atmosphere.

Secondly, the concentrations of atomic oxygen, nitric oxide and other atmospheric components are rather less than concentrations of $\mathrm{N}_{2}$ and $\mathrm{O}_{2}$ and the collisional part of the kinetics of $\mathrm{N}_{2}$ and $\mathrm{O}_{2}$ can be considered in the frames of $\mathrm{N}_{2}-\mathrm{N}_{2}, \mathrm{~N}_{2}-\mathrm{O}_{2}, \mathrm{O}_{2}-\mathrm{O}_{2}$ collisions. Therefore the conclusions of the studies for auroral ionosphere can be applied to the conditions of a laboratory discharge in a mixture of $\mathrm{N}_{2}$ and $\mathrm{O}_{2}$ atmospheric gases and vice versa.

Despite some questions in current understanding of $\mathrm{N}_{2}$ electronic kinetics and processes related with the nitrogen afterglow in the laboratory (Guerra et al., 2007), the mixtures of $\mathrm{N}_{2}$ with $\mathrm{O}_{2}$ have a more complicated kinetics. Oxygen molecules take part strongly in the quenching of electronically excited states of $\mathrm{N}_{2}$, making the overall electronic kinetics depending on the fractions of $\mathrm{O}_{2}$ and $\mathrm{N}_{2}$ in the mixture. Several investigators have observed an increase in the $\mathrm{N}$ atom concentration in the discharge and in the afterglow when $\mathrm{O}_{2}$ was added into the active $\mathrm{N}_{2}$ discharge (Nahorny et al., 1995; Ricard et al., 2001). When no admixture of $\mathrm{O}_{2}$ is added, the $\mathrm{N}$ atom density is usually very low.

Kamaratos $(1997,2006)$ deduced intensity enhancements of 1PG afterglow emissions of $\mathrm{N}_{2}$ from experiments when discharged oxygen was added to active nitrogen mixed with oxygen. He believed that the reaction of metastable molecules $\mathrm{N}_{2}\left(\mathrm{~A}^{3} \Sigma_{u}^{+}\right)$and $\mathrm{O}_{2}\left(a^{1} \Delta_{g}\right)$ might play a more important role in the formation of $\mathrm{N}_{2}\left(\mathrm{~B}^{3} \Pi_{g}\right)$ in the afterglow stage. Moreover, Kamaratos (2009) pointed out that the role of ground state $\mathrm{O}_{2}$ in producing $\mathrm{N}_{2}\left(\mathrm{~B}^{3} \Pi_{g}\right)$ in a sprite streamer should also be taken into account. Experimental measurements by Umemoto et al. (2003) have identified a production of $\mathrm{N}_{2}\left(\mathrm{~B}^{3} \Pi_{g}\right)$ in the collisional deactivation of $\mathrm{N}_{2}\left(a^{\prime 1} \Sigma_{u}^{-}, v=0\right)$ by different atomic and molecular gases. Their results have clearly shown that $\mathrm{N}_{2}\left(\mathrm{~B}^{3} \Pi_{g}, v=0\right)$ is effectively produced in the reactions of $\mathrm{N}_{2}\left(a^{\prime 1} \Sigma_{u}^{-}, v=0\right)$ with

Published by Copernicus Publications on behalf of the European Geosciences Union. 
molecular oxygen but the production by $\mathrm{N}_{2}$ molecules is minor.

When two oxygen atoms recombine in three-body collisions at the altitudes of lower thermosphere and mesosphere $(85-100 \mathrm{~km})$, a significant fraction of produced oxygen molecules have the energy near the dissociation limit (Bates, 1988). In the earth's atmosphere, nightglow emission is observed from all three Herzberg states of $\mathrm{O}_{2}\left(\mathrm{~A}^{3} \Sigma_{u}^{+}, \mathrm{A}^{\prime 3} \Delta_{u}\right.$, $c^{1} \Sigma_{u}^{-}$). The $\mathrm{A}^{3} \Sigma_{u}^{+}-\mathrm{X}^{3} \Sigma_{g}^{-}$(Herzberg I), $c^{1} \Sigma_{u}^{-}-\mathrm{X}^{3} \Sigma_{g}^{-}$ (Herzberg II) and $\mathrm{A}^{\prime 3} \Delta_{u}-a^{1} \Delta_{g}$ (Chamberlain) electronic transitions cause the dominant emissions in the ultraviolet and blue spectral regions of the nightglow in the earth's atmosphere. Because of long radiative lifetimes of Herzberg states, collisions play a principal role in electronic kinetics of $\mathrm{O}_{2}$ in the region of lower thermosphere and mesosphere and in their emission intensities. Molecular nitrogen takes part not only in the quenching of the states of $\mathrm{O}_{2}$, but also the interaction of metastable nitrogen $\mathrm{N}_{2}\left(\mathrm{~A}^{3} \Sigma_{u}^{+}\right)$with oxygen molecules initiates the dissociative processes (Kirillov, 2008b).

Main aim of the paper is the study of electronic kinetics of metastable $\mathrm{N}_{2}$ and $\mathrm{O}_{2}$ in the region of lower thermosphere and mesosphere. Firstly we suggest a set of calculated quenching rate coefficients for the $\mathrm{A}^{3} \Sigma_{u}^{+}, c^{1} \Sigma_{u}^{-}$, $\mathrm{A}^{\prime 3} \Delta_{u}$ states of $\mathrm{O}_{2}$ and the $\mathrm{A}^{3} \Sigma_{u}^{+}, \mathrm{W}^{3} \Delta_{u}, \mathrm{~B}^{\prime 3} \Sigma_{u}^{-}$states of $\mathrm{N}_{2}$. Applying the quenching coefficients we will see in this work that electronic kinetics of $\mathrm{N}_{2}$ influences on the kinetics of $\mathrm{O}_{2}$ in high-laltitude lower thermosphere and mesosphere. In order to simplify the study, herein we decided to limit our investigation on the mixture of two gases $\mathrm{O}_{2}$ and $\mathrm{N}_{2}$.

\section{Intramolecular versus intermolecular electron en- ergy transfer processes in the quenching of $\mathrm{O}_{2}\left(c^{1} \Sigma_{u}^{-}\right.$,} $\left.\mathrm{A}^{\prime 3} \Delta_{u}, \mathrm{~A}^{3} \Sigma_{u}^{+}\right)$and $\mathrm{N}_{2}\left(\mathrm{~A}^{3} \Sigma_{u}^{+}, \mathrm{W}^{3} \Delta_{u}, \mathrm{~B}^{\prime 3} \Sigma_{u}^{-}\right)$

Kirillov (2008b) has shown that intermolecular electron energy transfers play a very important role in the processes of the electronic quenching of metastable nitrogen $\mathrm{N}_{2}\left(\mathrm{~A}^{3} \Sigma_{u}^{+}\right)$in the collisions with $\mathrm{N}_{2}$ and $\mathrm{O}_{2}$ and singlet oxygen $\mathrm{O}_{2}\left(a^{1} \Delta_{g}, b^{1} \Sigma_{g}^{+}\right)$in the collisions with $\mathrm{O}_{2}$. These intermolecular transfers are dominant for many vibrational levels of the considered states of $\mathrm{N}_{2}$ and $\mathrm{O}_{2}$. By the way, very good agreement of the calculated rate coefficients with a few available experimental data was obtained in that paper.

Here we continue similar estimations of total quenching rate coefficients for Herzberg $c^{1} \Sigma_{u}^{-}, \mathrm{A}^{\prime 3} \Delta_{u}, \mathrm{~A}^{3} \Sigma_{u}^{+}$states of molecular oxygen and for the $\mathrm{A}^{3} \Sigma_{u}^{+}, \mathrm{W}^{3} \Delta_{u}, \mathrm{~B}^{\prime \prime} \Sigma_{u}^{-}$states of molecular nitrogen according to analytical expressions of Kirillov (2004a). As in Kirillov (2008b) we use analytical expressions for the rate coefficients of electronic quenching in molecular collisions based on quantum-mechanical LandauZener and Rosen-Zener approximations and presented by Kirillov (2004a). These approximations are very useful in the cases of the crossing and non-crossing of potential sur- faces for atom-molecular collisions (see Fig. 8 of Nakamura, 1992, or Fig. 1 of Zhu and Lin, 2006). We apply the LandauZener approximation for the non-adiabatic transition in the case of the crossing and the Rosen-Zener approximation in the case of the non-crossing.

Herzberg states of $\mathrm{O}_{2}$ arise from the same molecular orbital configuration $1 \sigma_{g}^{2} 1 \sigma_{u}^{2} 2 \sigma_{g}^{2} 2 \sigma_{u}^{2} 3 \sigma_{g}^{2} 1 \pi_{u}^{3} 1 \pi_{g}^{3}$. Principal difference of the states consists in the distribution of 6 electrons between $\pi_{u+}, \pi_{g+}$ and $\pi_{u-}, \pi_{g-}$ valence orbitals (Slater, 1963). Here the subscripts + and - means "positive" and "negative" orbital projections. For example, the $c^{1} \Sigma_{u}^{-}$ and $\mathrm{A}^{3} \Sigma_{u}^{+}$states have odd numbers of the orbitals with "positive" and "negative" projections, but the $\mathrm{A}^{\prime 3} \Delta_{u}$ state has even numbers. We assume in our calculation that there are the transitions between the valence orbitals during molecular collisions. Also we take into account $1 \pi_{g} \rightarrow 1 \pi_{u}$ transitions with the production of $\mathrm{X}^{3} \Sigma_{g}^{-}, a^{1} \Delta_{g}$ and $b^{1} \Sigma_{g}^{+}$states. Therefore, our calculation of total quenching rate coefficients for Herzberg states of molecular oxygen in the collisions with $\mathrm{O}_{2}$ includes contributions of intramolecular and intermolecular processes

$$
\mathrm{O}_{2}(Y, v)+\mathrm{O}_{2}\left(\mathrm{X}^{3}, v=0\right) \rightarrow \mathrm{O}_{2}\left(Y^{\prime}, Z, \mathrm{X}^{3}, v^{\prime}\right)+\mathrm{O}_{2}\left(\mathrm{X}^{3}, v=0\right),
$$

$\mathrm{O}_{2}(Y, v)+\mathrm{O}_{2}\left(\mathrm{X}^{3}, v=0\right) \rightarrow \mathrm{O}_{2}\left(\mathrm{X}^{3}, v^{\prime \prime} \geq 0\right)+\mathrm{O}_{2}\left(Y, Y^{\prime}, Z, v^{\prime}\right)$,

where $Y, Y$ are the $c^{1} \Sigma_{u}^{-}, \mathrm{A}^{\prime 3} \Delta_{u}, \mathrm{~A}^{3} \Sigma_{u}^{+}$states and $Z$ are the $a^{1} \Delta_{g}, b^{1} \Sigma_{g}^{+}$states.

Results of our calculations of total quenching rate coefficients for Herzberg states of molecular oxygen are plotted in Figs. 1-3. A comparison of the calculated coefficients for the $\mathrm{A}^{3} \Sigma_{u}^{+}$state with experimental data by Knutsen et al. (1994), Copeland et al. (1994), Slanger et al. (1984) shows a good agreement for vibrational levels $v=6,7,9,10$. By the way, Copeland et al. (1994) and Slanger et al. (1984) have obtained lowest limits for the coefficients of $v=8$ and 10 (Pejacovic et al., 2007, Table 2). We have not found good agreement of the calculated coefficients for the $c^{1} \Sigma_{u}^{-}$state with experimental data by Copeland et al. (1996) and Wouters et al. (2002). But in any case both experimental and calculated values show some oscillations in the region of $v \geq 8$.

The sums of the corresponding contributions of intramolecular (1a) and intermolecular (1b) processes are also presented in Figs. 1-3. It is seen that intramolecular processes dominate in the quenching of the $c^{1} \Sigma_{u}^{-}(v \geq 3)$, $\mathrm{A}^{\prime 3} \Delta_{u}(v \geq 2), \mathrm{A}^{3} \Sigma_{u}^{+}$states.

Since electron energy of the $\mathrm{A}^{3} \Sigma_{u}^{+}$state of $\mathrm{N}_{2}(\sim 6.2 \mathrm{eV})$ is much greater than the energies of highest vibrational levels of Herzberg states of $\mathrm{O}_{2}(\sim 5.1 \mathrm{eV})$, so we believe that intramolecular electron energy transfer processes

$\mathrm{O}_{2}(Y, v)+\mathrm{N}_{2}\left(X^{1}, v=0\right) \rightarrow \mathrm{O}_{2}\left(Y^{\prime}, Z, \mathrm{X}^{3}, v^{\prime}\right)+\mathrm{N}_{2}\left(\mathrm{X}^{1}, v=0\right)(2)$ 


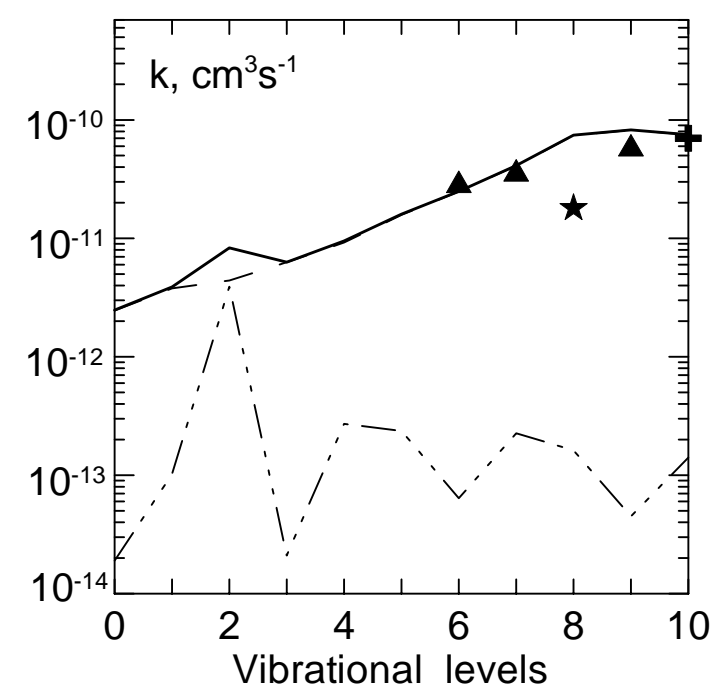

Fig. 1. The calculated quenching rate coefficients of $\mathrm{O}_{2}\left(\mathrm{~A}^{3} \Sigma_{u}^{+}\right.$, $v=0-10)+\mathrm{O}_{2}$ (solid line) are compared with experimental data by Knutsen et al. (1994) (triangles), Copeland et al. (1994) (star), Slanger et al. (1984) (cross). Dashed line and dash and three dotted line are the contributions of intramolecular and intermolecular electron energy transfer processes, respectively.

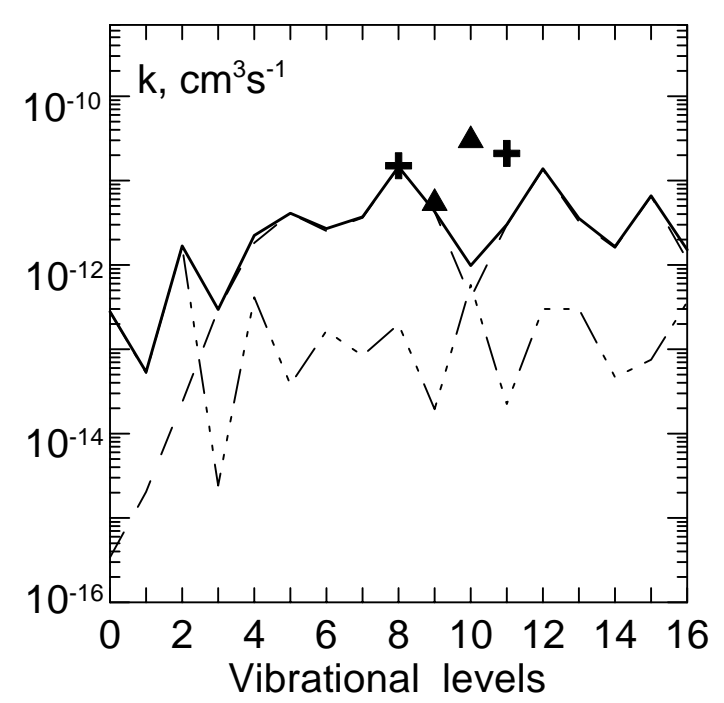

Fig. 2. The calculated quenching rate coefficients of $\mathrm{O}_{2}\left(c^{1} \Sigma_{u}^{-}\right.$, $v=0-16)+\mathrm{O}_{2}$ (solid line) are compared with experimental data by Copeland et al. (1996) and Wouters et al. (2002) (triangles at $T=300 \mathrm{~K}$, crosses at $T=245 \mathrm{~K}$ ). Dashed line and dash and three dotted line are the contributions of intramolecular and intermolecular electron energy transfer processes, respectively.

dominate in the quenching of Herzberg states by molecular nitrogen. The sums of the contributions of intramolecular processes for the $\mathrm{A}^{3} \Sigma_{u}^{+}$and $c^{1} \Sigma_{u}^{-}$states are compared with experimental data of Knutsen et al. (1994) and Copeland et al. (1996), obtained for the quenching by $\mathrm{N}_{2}$, in Figs. 4 and

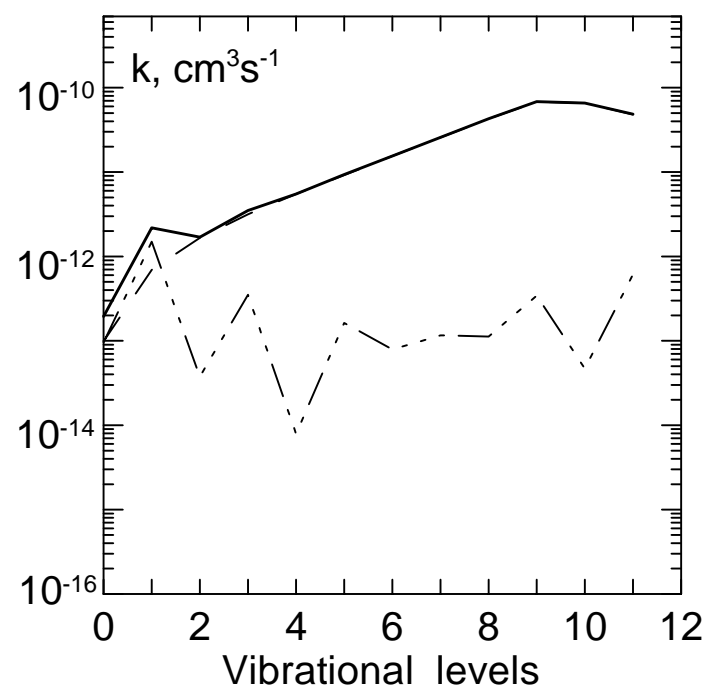

Fig. 3. The calculated quenching rate coefficients of $\mathrm{O}_{2}\left(\mathrm{~A}^{\prime 3} \Delta_{u}\right.$, $v=0-11)+\mathrm{O}_{2}-$ solid line. Dashed line and dash and three dotted line are the contributions of intramolecular and intermolecular electron energy transfer processes, respectively.

5 , respectively. Better agreement of our results with experimental data could be received in the case of a normalising of calculated values by factors 0.6 for the $\mathrm{A}^{3} \Sigma_{u}^{+}$state and 0.8 for the $c^{1} \Sigma_{u}^{-}$state.

As in the case of Herzberg states of $\mathrm{O}_{2}$ the main difference of the $\mathrm{A}^{3} \Sigma_{u}^{+}, \mathrm{W}^{3} \Delta_{u}, \mathrm{~B}^{\prime 3} \Sigma_{u}^{-}$states of $\mathrm{N}_{2}$ from the ground $\mathrm{X}^{1} \Sigma_{g}^{+}$state consists in the $1 \pi_{u} \rightarrow 1 \pi_{g}$ transition in molecular orbital configuration. The $\mathrm{A}^{3} \Sigma_{u}^{+}$and $\mathrm{B}^{\prime 3} \Sigma_{u}^{-}$states are related with even numbers of electrons on "positive" $\left(\pi_{u+}\right.$, $\left.\pi_{g+}\right)$ and "negative" $\left(\pi_{u-}, \pi_{g_{-}}\right)$orbitals, but the $\mathrm{W}^{3} \Delta_{u}$ state is specified by odd numbers (Slater, 1963). The calculation of total quenching rate coefficients for the states of molecular nitrogen in the collisions with $\mathrm{N}_{2}$ includes contributions of intramolecular and intermolecular electron energy transfer processes

$$
\begin{aligned}
& \mathrm{N}_{2}(Y, v)+\mathrm{N}_{2}\left(\mathrm{X}^{1}, v=0\right) \rightarrow \mathrm{N}_{2}\left(\mathrm{~B}^{3}, \mathrm{X}^{1}, v^{\prime}\right)+\mathrm{N}_{2}\left(\mathrm{X}^{1}, v=0\right),(3 \mathrm{a}) \\
& \mathrm{N}_{2}(Y, v)+\mathrm{N}_{2}\left(\mathrm{X}^{1}, v=0\right) \rightarrow \mathrm{N}_{2}\left(\mathrm{X}^{1}, v^{\prime \prime} \geq 0\right)+\mathrm{N}_{2}\left(Y, Y^{\prime}, \mathrm{B}^{3}, v^{\prime}\right)
\end{aligned}
$$

where $Y$ and $Y$ ' means the $\mathrm{A}^{3} \Sigma_{u}^{+}, \mathrm{W}^{3} \Delta_{u}, \mathrm{~B}^{\prime 3} \Sigma_{u}^{-}$states. It was obtained in the calculation that intramolecular processes are negligible in the excitation of the ground $\mathrm{X}^{1} \Sigma_{g}^{+}$state and related mainly with the $1 \pi_{u} \rightarrow 3 \sigma_{g}$ transition producing the $\mathrm{B}^{3} \Pi_{g}$ state. Here we could include the transitions between these three states of the same molecular orbital configuration, but the potential curves of the states have similar values of equilibrium internuclear distances, frequency and anharmonic constants (Lofthus and Krupenie, 1977) and corresponding Franck-Condon factors in the calculation are very small. 


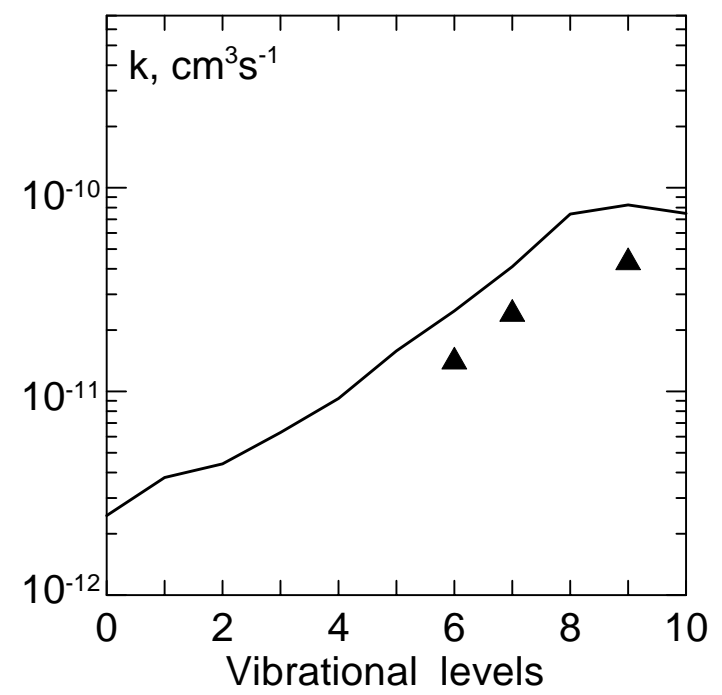

Fig. 4. The calculated quenching rate coefficients of $\mathrm{O}_{2}\left(\mathrm{~A}^{3} \Sigma_{u}^{+}\right.$, $v=0-10)+\mathrm{N}_{2}$ (solid line) are compared with experimental data by Knutsen et al. (1994) (triangles).

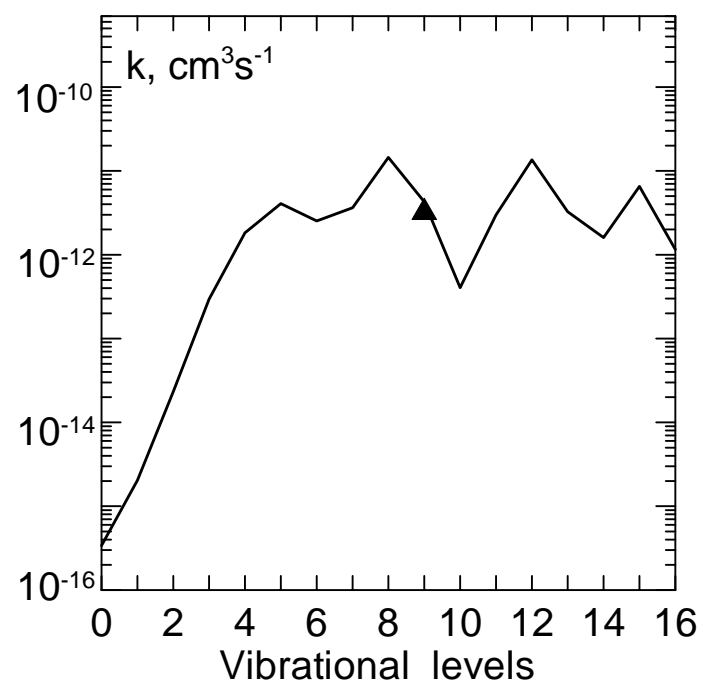

Fig. 5. The calculated quenching rate coefficients of $\mathrm{O}_{2}\left(c^{1} \Sigma_{u}^{-}\right.$, $v=0-16)+\mathrm{N}_{2}$ (solid line) are compared with experimental data by Copeland et al. (1996) (triangle).

Results of our calculations for total quenching rate coefficient of $\mathrm{N}_{2}\left(\mathrm{~A}^{3} \Sigma_{u}^{+}, v=2-23\right)$ in the collisions with $\mathrm{N}_{2}$ are shown in Fig. 6 and compared with experimental data by Dreyer and Perner (1973). It is seen that there is a good agreement of theoretical and experimental results in the magnitude and in the tendency of an enhancement with the rise of vibrational level number for $v=2-7$. Our calculation has pointed out that intermolecular process (3b) with the production of the $\mathrm{A}^{3} \Sigma_{u}^{+}$state dominates in the quenching for vibrational levels $v=2-6$ of the $\mathrm{A}^{3} \Sigma_{u}^{+}$state. Moreover, it is obtained that the product states $\mathrm{X}^{1} \Sigma_{g}^{+}, v^{\prime \prime}=1$ and $\mathrm{A}^{3} \Sigma_{u}^{+}$,

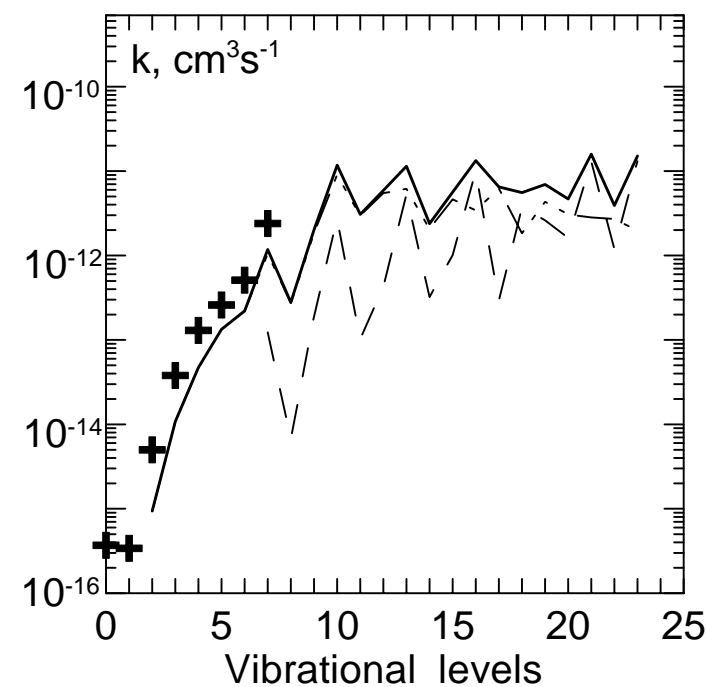

Fig. 6. The calculated quenching rate coefficients of $\mathrm{N}_{2}\left(\mathrm{~A}^{3} \Sigma_{u}^{+}\right.$, $v=2-23)+\mathrm{N}_{2}$ (solid line) are compared with experimental data by Dreyer and Perner (1973) (crosses). Dashed line and dash and three dotted line are the contributions of intramolecular and intermolecular electron energy transfer processes, respectively.

$v^{\prime}=v-2$ are principal in the process (3b). This fact is in good agreement with experimental conclusions of Dreyer and Perner (1973). The sum of the processes (3a) and (3b) with the production of the $\mathrm{B}^{3} \Pi_{g}$ state is mainly responsible for the quenching of vibrational levels $v \geq 7$. The efficiencies of the processes depend on vibrational level $v$. For example, the process (3a) prevails for levels $v=14-15$ and the process (3b) prevails for level $v=16$.

Results of our calculations for total quenching rate coefficients of $\mathrm{N}_{2}\left(\mathrm{~W}^{3} \Delta_{u}, v=0-18\right), \mathrm{N}_{2}\left(\mathrm{~B}^{\prime 3} \Sigma_{u}^{-}, v=0-13\right)$ in the collisions with $\mathrm{N}_{2}$ are shown in Figs. 7 and 8, respectively. It is obtained in the calculations that main contributions in the quenching are from intramolecular processes (3a) and intermolecular processes $(3 \mathrm{~b})$ with the production of two other states of the same orbital configuration $Y$ \%

The contributions of intramolecular and intermolecular electron energy transfer processes in the quenching of the $\mathrm{A}^{3} \Sigma_{u}^{+}, \mathrm{W}^{3} \Delta_{u}, \mathrm{~B}^{\prime 3} \Sigma_{u}^{-}$states are presented in Figs. 6-8. The dominance of intermolecular processes for lowest vibrational levels of the $\mathrm{A}^{3} \Sigma_{u}^{+}$state is similar to the behaviour of the $c^{1} \Sigma_{u}^{-}$state of $\mathrm{O}_{2}$. Both states have lowest electron energy from considered three states of the same molecular orbital configuration of $\mathrm{O}_{2}$ and $\mathrm{N}_{2}$.

Finally we have calculated the quenching rate coefficients for the collision of metastable molecular nitrogen $\mathrm{N}_{2}\left(\mathrm{~A}^{3} \Sigma_{u}^{+}\right)$ with the ground state $\mathrm{O}_{2}$ molecules. The calculation of total quenching rate coefficients includes contributions of intramolecular and intermolecular processes

$$
\mathrm{N}_{2}\left(\mathrm{~A}^{3}, v\right)+\mathrm{O}_{2}\left(\mathrm{X}^{3}, v=0\right) \rightarrow \mathrm{N}_{2}\left(\mathrm{~B}^{3}, v^{\prime \prime}\right)+\mathrm{O}_{2}\left(\mathrm{X}^{3}, v=0\right)
$$




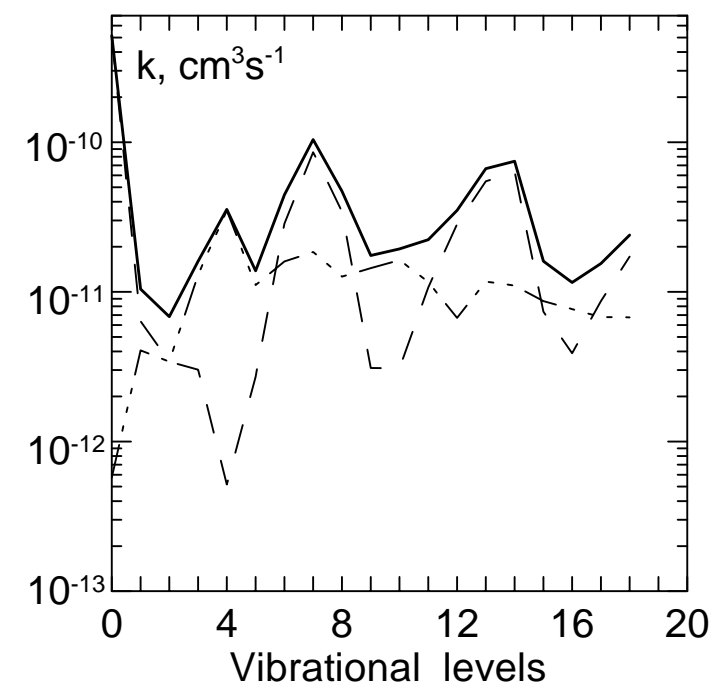

Fig. 7. The calculated quenching rate coefficients of $\mathrm{N}_{2}\left(\mathrm{~W}^{3} \Delta_{u}\right.$, $v=0-18)+\mathrm{N}_{2}-$ solid line. Dashed line and dash and three dotted line are the contributions of intramolecular and intermolecular electron energy transfer processes, respectively.

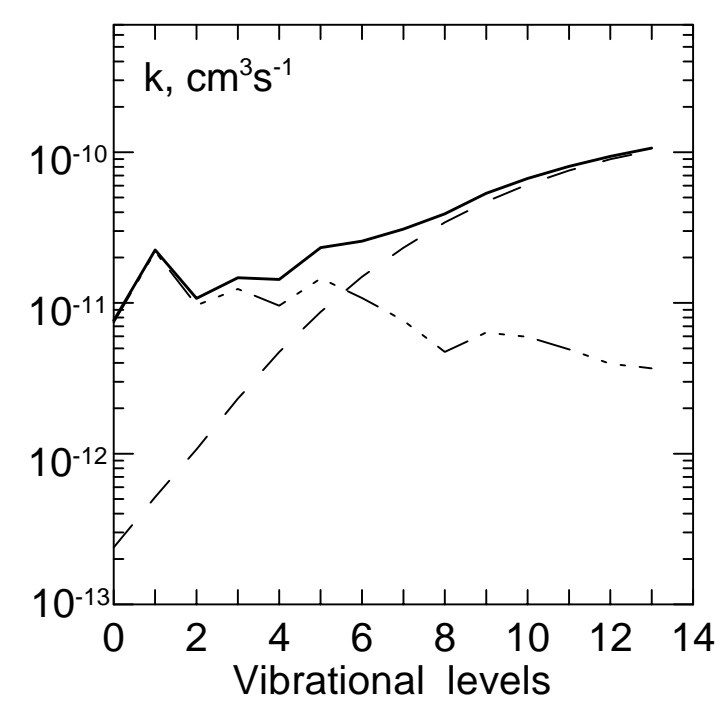

Fig. 8. The calculated quenching rate coefficients of $\mathrm{N}_{2}\left(\mathrm{~B}^{\prime 3} \Sigma_{u}^{-}\right.$, $v=0-13)+\mathrm{N}_{2}-$ solid line. Dashed line and dash and three dotted line are the contributions of intramolecular and intermolecular electron energy transfer processes, respectively.

$\mathrm{N}_{2}\left(\mathrm{~A}^{3}, v\right)+\mathrm{O}_{2}\left(\mathrm{X}^{3}, v=0\right) \rightarrow \mathrm{N}_{2}\left(\mathrm{X}^{1}, v^{\prime \prime} \geq 0\right)+\mathrm{O}_{2}\left(Y, v^{\prime}\right)$

or $\mathrm{O}\left({ }^{3} \mathrm{P}\right)+\mathrm{O}\left({ }^{3} \mathrm{P},{ }^{1} \mathrm{D}\right)$

where $Y$ means the $c^{1} \Sigma_{u}^{-}, \mathrm{A}^{\prime 3} \Delta_{u}, \mathrm{~A}^{3} \Sigma_{u}^{+}, \mathrm{B}^{3} \Sigma_{u}^{-}$states of molecular oxygen. The calculated total quenching rate coefficients for $\mathrm{N}_{2}\left(\mathrm{~A}^{3} \Sigma_{u}^{+}, v=0-23\right)$ are compared with experimental data by Dreyer et al. (1974); Thomas and Kaufman (1985); De Benedictis and Dilecce (1997) in Fig. 9. The application of Franck-Condon densities for processes (4b) with

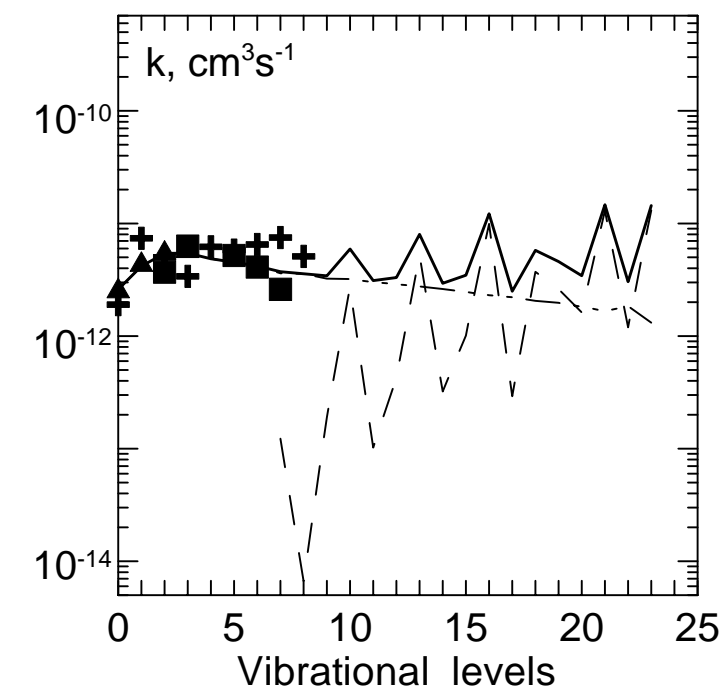

Fig. 9. The calculated quenching rate coefficients of $\mathrm{N}_{2}\left(\mathrm{~A}^{3} \Sigma_{u}^{+}\right.$, $v=0-23)+\mathrm{O}_{2}$ (solid line) are compared with experimental data of Dreyer et al. (1974) (crosses), Thomas and Kaufman (1985) (triangles), De Benedictis and Dilecce (1997) (squares). Dashed line and dash and three dotted line are the contributions of intramolecular and intermolecular electron energy transfer processes, respectively.

the dissociation of oxygen molecule is described by Kirillov (2008b).

\section{Model}

The model of vibrational populations of electronically excited states of $\mathrm{N}_{2}$ and $\mathrm{O}_{2}$ is similar to the one by Kirillov (2008a). Here we consider three principal processes responsible for the electronic excitation and quenching of triplet $\mathrm{N}_{2}$ and electronically excited $\mathrm{O}_{2}$ :

1. The electronic excitation by auroral electron impact

$\mathrm{N}_{2}\left(\mathrm{X}^{1}, v=0\right)+e_{a} \rightarrow \mathrm{N}_{2}\left(\gamma, v^{\prime}\right)+e_{a}$,

where $\gamma=\mathrm{A}^{3} \Sigma_{u}^{+}, \mathrm{W}^{3} \Delta_{u}, \mathrm{~B}^{3} \Pi_{g}, \mathrm{~B}^{\prime} \Sigma_{u}^{-}, \mathrm{C}^{3} \Pi_{u}$ and

$\mathrm{O}_{2}\left(\mathrm{X}^{3}, v=0\right)+e_{a} \rightarrow \mathrm{O}_{2}\left(\gamma, v^{\prime}\right)+e_{a}$,

where $\gamma=a^{1} \Delta_{g}, b^{1} \Sigma_{g}^{+}, c^{1} \Sigma_{u}^{-}, \mathrm{A}^{\prime 3} \Delta_{u}, \mathrm{~A}^{3} \Sigma_{u}^{+}$. As in Kirillov (2008a) we apply the method of "excitation energy costs" in the estimation of the rates of electronic excitation by electron impact.

2. Spontaneous radiative transitions

$$
\begin{aligned}
& \mathrm{N}_{2}\left(\mathrm{~B}^{3}, v\right) \leftrightarrow \mathrm{N}_{2}\left(\mathrm{~A}^{3}, v^{\prime}\right) \pm h v_{1 \mathrm{PG}}, \\
& \mathrm{N}_{2}\left(\mathrm{~B}^{3}, v\right) \leftrightarrow \mathrm{N}_{2}\left(\mathrm{~W}^{3}, v^{\prime}\right) \pm h v_{\mathrm{WB}},
\end{aligned}
$$




$$
\begin{aligned}
& \mathrm{N}_{2}\left(\mathrm{~B}^{3}, v\right) \leftrightarrow \mathrm{N}_{2}\left(\mathrm{~B}^{\prime 3}, v^{\prime}\right) \pm h v_{\mathrm{AG}} \\
& \mathrm{N}_{2}\left(\mathrm{C}^{3}, v\right) \rightarrow \mathrm{N}_{2}\left(\mathrm{~B}^{3}, v^{\prime}\right)+h v_{2 \mathrm{PG}}, \\
& \mathrm{N}_{2}\left(\mathrm{~A}^{3}, v\right) \rightarrow \mathrm{N}_{2}\left(\mathrm{X}^{1}, v^{\prime}\right)+h v_{\mathrm{VK}}
\end{aligned}
$$

for molecular nitrogen and

$$
\begin{aligned}
& \mathrm{O}_{2}\left(\mathrm{~A}^{3}, v\right) \rightarrow \mathrm{O}_{2}\left(\mathrm{X}^{3}, v^{\prime}\right)+h v_{\mathrm{HI}}, \\
& \mathrm{O}_{2}\left(c^{1}, v\right) \rightarrow \mathrm{O}_{2}\left(\mathrm{X}^{3}, v^{\prime}\right)+h v_{\mathrm{HII}} \\
& \mathrm{O}_{2}\left(\mathrm{~A}^{\prime 3}, v\right) \rightarrow \mathrm{O}_{2}\left(\mathrm{X}^{3}, v^{\prime}\right)+h v_{\mathrm{HIII}}, \\
& \mathrm{O}_{2}\left(\mathrm{~A}^{\prime 3}, v\right) \rightarrow \mathrm{O}_{2}\left(a^{1}, v^{\prime}\right)+h v_{\mathrm{C}}, \\
& \mathrm{O}_{2}\left(b^{1}, v\right) \rightarrow \mathrm{O}_{2}\left(\mathrm{X}^{3}, v^{\prime}\right)+h v_{\mathrm{A}}, \\
& \mathrm{O}_{2}\left(a^{1}, v\right) \rightarrow \mathrm{O}_{2}\left(\mathrm{X}^{3}, v^{\prime}\right)+h v_{\mathrm{AIR}}
\end{aligned}
$$

for molecular oxygen. The sign \pm in the processes $(7 \mathrm{a}-$ c) means the evidence of direct and reverse spontaneous transitions between considered states.

3. Intermolecular and intramolecular electron energy transfers in molecular collisions described in the Sect. 2 and by Kirillov (2004b, 2008b).

Spontaneous radiational transitions and intramolecular and intermolecular electron energy transfers are considered as quenching processes for higher states and as excitation ones for lowest states. Einstein coefficients for radiational spontaneous transitions $(7 \mathrm{a}-\mathrm{e})$ are taken according to Gilmore et al. (1992). Einstein coefficients for radiational spontaneous transitions (8a-d) and (8e, f) are taken according to Bates (1989) and Vallance Jones (1974, Tables 4.15 and 4.16), respectively.

\section{Vibrational population of electronically excited $\mathbf{N}_{2}$}

The study of electronically excited $\mathrm{N}_{2}$ is limited only on five $\mathrm{A}^{3} \Sigma_{u}^{+}(v=0-23), \mathrm{B}^{3} \Pi_{g}(v=0-12), \mathrm{W}^{3} \Delta_{u}(v=0-18), \mathrm{B}^{\prime 3} \Sigma_{u}^{-}$ $(v=0-13), \mathrm{C}^{3} \Pi_{u}(v=0-4)$ triplet states of $\mathrm{N}_{2}$. The quenching rate coefficients of the $\mathrm{A}^{3} \Sigma_{u}^{+}, \mathrm{W}^{3} \Delta_{u}, \mathrm{~B}^{\prime 3} \Sigma_{u}^{-}$states for the collisions $\mathrm{N}_{2} *-\mathrm{N}_{2}$ and $\mathrm{N}_{2}\left(\mathrm{~A}^{3} \Sigma_{u}^{+}\right)-\mathrm{O}_{2}$ are taken according to Figs. 6-9 and for the $\mathrm{N}_{2}\left(\mathrm{~B}^{3} \Pi_{g}\right)-\mathrm{N}_{2}$ collisions according to (Kirillov, 2004b). The quenching rate coefficients for lowest vibrational levels $v=0,1$ of the $\mathrm{N}_{2}\left(\mathrm{~A}^{3} \Sigma_{u}^{+}\right)$molecule in the collisions with $\mathrm{N}_{2}$ accepted according to experimental data by Dreyer and Perner (1973). Intramolecular electron energy transfer process with energetically quasi-resonant vibrational excitation of the ground $\mathrm{X}^{1} \Sigma_{g}^{+}$state with $v=25,26$ is the only possible mechanism of the removal. As in Kirillov (2008a) collisional quenching processes for the $\mathrm{C}^{3} \Pi_{u}$ state are not included in this consideration since radiational lifetime is sufficiently less than collisional one for the state at the altitudes of lower thermosphere and mesosphere. Also in contrast with Morrill and Benesch (1996) we do not consider any contribution of $\mathrm{E}^{3} \Sigma_{g}^{+}$and $\mathrm{D}^{3} \Sigma_{u}^{+}$states in vibrational populations of mentioned five triplet states. Excitation rates of these two states according to Sergienko and Ivanov (1993) are too small to be taken into consideration.

In this paper we pay special attention to the presentation of vibrational populations of the $\mathrm{A}^{3} \Sigma_{u}^{+}$state of $\mathrm{N}_{2}$ for conditions of auroral lower thermosphere and mesosphere. Metastable molecular nitrogen $\mathrm{N}_{2}\left(\mathrm{~A}^{3} \Sigma_{u}^{+}\right)$could be considered as a possible precursor for important chemical processes (Swider, 1976; Zipf, 1980; Campbell et al., 2007; Campbell and Brunger, 2007). To calculate the population $N_{v}^{A}$ of the $v$ th vibrational level of the $\mathrm{A}^{3} \Sigma_{u}^{+}$state we use the steady-state equation:

$$
\begin{array}{r}
\mathrm{Q}^{\mathrm{A}} \cdot q_{v}^{A}+\sum_{v \prime} A_{v \prime v}^{\mathrm{BA}} \cdot N_{v^{\prime}}^{B}+\sum_{Y=A, W, B, B \prime ; v^{\prime}} k_{v \prime v}^{* \mathrm{YA}}\left[\mathrm{N}_{2}\right] \cdot N_{v \prime}^{Y} \\
+\sum_{v \prime} k_{v \prime v}^{\dagger \mathrm{BA}}\left(\left[\mathrm{N}_{2}\right]+\left[\mathrm{O}_{2}\right]\right) \cdot N_{v \prime}^{B}=\left\{\sum_{v \prime} A_{v v^{\prime}}^{\mathrm{AB}}+\sum_{v \prime} A_{v v^{\prime}}^{\mathrm{AX}}\right. \\
+\sum_{Y=A, W, B, B \prime ; v^{\prime}} k_{v v^{\prime}}^{* \mathrm{AY}}\left[\mathrm{N}_{2}\right]+\sum_{v \prime} k_{v v^{\prime}}^{\dagger \mathrm{AB}}\left(\left[\mathrm{N}_{2}\right]+\left[\mathrm{O}_{2}\right]\right) \\
\left.+k_{v v^{\prime}}^{\dagger \mathrm{AX}}\left(\left[\mathrm{N}_{2}\right]+\left[\mathrm{O}_{2}\right]\right)+k_{v}^{* \mathrm{AO} 2}\left[\mathrm{O}_{2}\right]\right\} \cdot N_{v}^{A},
\end{array}
$$

where $\mathrm{Q}^{\mathrm{A}}$ is the production rate of this state by auroral electrons (in $\mathrm{cm}^{-3} \mathrm{~s}^{-1}$ ), $q_{v}^{A}$ is the Franck-Condon factor for the transition $\mathrm{X}^{1} \Sigma_{g}^{+}, v=0 \rightarrow \mathrm{A}^{3} \Sigma_{u}^{+}, v, A_{v \prime v}^{\mathrm{BA}}, A_{v v \prime}^{\mathrm{AB}}, A_{v v^{\prime}}^{\mathrm{AX}}$ are Einstein probabilities for the spontaneous transitions $\mathrm{B}^{3} \Pi_{g}$, $v^{\prime} \rightarrow \mathrm{A}^{3} \Sigma_{u}^{+}, v, \mathrm{~A}^{3} \Sigma_{u}^{+}, v \rightarrow \mathrm{B}^{3} \Pi_{g}, v^{\prime}, \mathrm{A}^{3} \Sigma_{u}^{+}, v \rightarrow \mathrm{X}^{1} \Sigma_{g}^{+}$, $v^{\prime}, k_{v v^{\prime}}^{* \mathrm{YZ}}$ and $k_{v v \prime}^{\dagger \mathrm{YZ}}$ are the rate coefficients for intermolecular and intramolecular electron energy transfer processes with the quenching of $Y, v$ and the excitation of $Z, v^{\prime}$, respectively. We suggest to consider the rate of an intramolecular process independent on the kind of the collision with $\mathrm{N}_{2}$ or $\mathrm{O}_{2}$. So the sum of concentrations $\left[\mathrm{N}_{2}\right]+\left[\mathrm{O}_{2}\right]$ is included in steadystate Eq. (9) for contributions of intramolecular processes. The main difference of this Eq. (9) from similar Eq. (8a) of Kirillov (2008a) is the inclusion of intramolecular electron energy transfer process $\mathrm{A}^{3} \Sigma_{u}^{+} \rightarrow \mathrm{X}^{1} \Sigma_{g}^{+}$for lowest levels of the metastable state. The populations $N_{v}^{Y}$ of $\mathrm{B}^{3} \Pi_{g}, \mathrm{~W}^{3} \Delta_{u}$, $\mathrm{B}^{\prime 3} \Sigma_{u}^{-}, \mathrm{C}^{3} \Pi_{u}$ states are calculated according to Eqs. (8b-e) of Kirillov (2008a). The rate coefficients for all intermolecular and intramolecular electron energy transfer processes are presented by Kirillov (2008a).

Figure 10 is a plot of the calculated relative vibrational populations of the $\mathrm{A}^{3} \Sigma_{u}^{+}$state of $\mathrm{N}_{2}$ $\left(\left[\mathrm{N}_{2}\left(\mathrm{~A}^{3} \Sigma_{u}^{+}, \mathrm{v}\right)\right] /\left[\mathrm{N}_{2}\left(\mathrm{~A}^{3} \Sigma_{u}^{+}, v=0\right)\right]\right)$ at the altitudes of 100 and $80 \mathrm{~km}$. This state is the source of Vegard-Kaplan emissions of molecular nitrogen in auroral ionosphere. The relative populations derived from experimental observations of Vegard-Kaplan (VK) intensities in auroral ionosphere and theoretical estimation are presented in Fig. 4 of Eastes and Sharp (1987). 


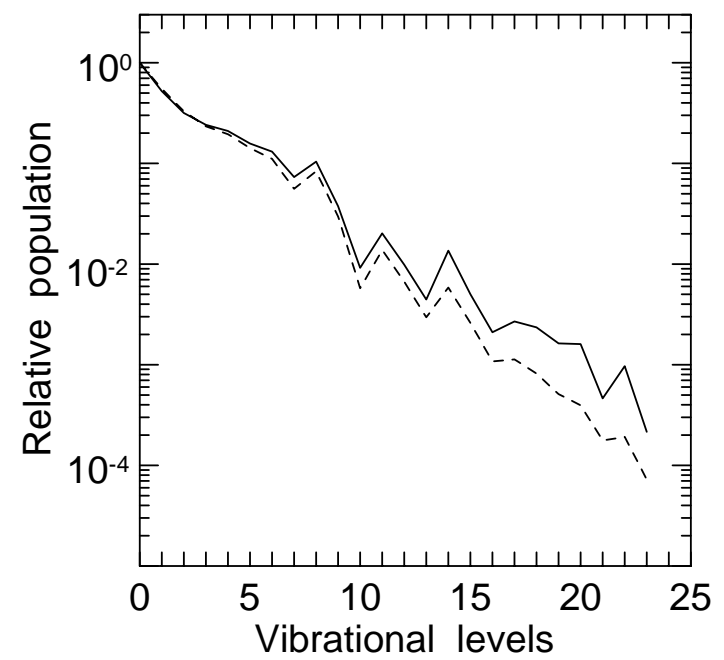

Fig. 10. The calculated relative vibrational populations $\left[\mathrm{N}_{2}\left(\mathrm{~A}^{3} \Sigma_{u}^{+}, \mathrm{v}\right)\right] /\left[\mathrm{N}_{2}\left(\mathrm{~A}^{3} \Sigma_{u}^{+}, v=0\right)\right]$ at altitudes of 100 and $80 \mathrm{~km}$ (dashed and solid lines, respectively).

Results of our calculation are similar to the data presented by Eastes and Sharp (1987) showing rapid decrease in the populations with the rise of vibrational level. Nevertheless, the results shown in Fig. 10 cannot be compared with the data of auroral observations as far as the intensities of VK emissions at the altitudes are much less than in E-region of the ionosphere and the kinetics of the $\mathrm{A}^{3} \Sigma_{u}^{+}$state is specified by collisional processes.

It is seen from Fig. 10 that the processes cause a redistribution of vibrational populations of the $\mathrm{A}^{3} \Sigma_{u}^{+}$state of $\mathrm{N}_{2}$ with the decrease of the altitude. As in a case with the $\mathrm{B}^{3} \Pi_{g}$ state (see Kirillov, 2008a) there is an enhancement of relative population of high vibrational levels with the rise in atmospheric density. The enhancement can be explained by important role of intramolecular electron energy transfer processes from the $\mathrm{B}^{3} \Pi_{g}$ state and of processes (3a) with $Y=\mathrm{W}^{3} \Delta_{u}, \mathrm{~B}^{\prime 3} \Sigma_{u}^{-}$(see Figs. 7 and 8). Therefore the collisional processes could be responsible for a change of relative intensities of bands in VK and 1PG systems of molecular nitrogen both in auroral ionosphere and for conditions of a laboratory discharge.

\section{Vibrational population of electronically excited $\mathrm{O}_{2}$}

The study of electronically excited $\mathrm{O}_{2}$ is limited on five lowest electronically excited states $a^{1} \Delta_{g}(v=0-33), b^{1} \Sigma_{g}^{+}(v=0$ 30), $c^{1} \Sigma_{u}^{-}(v=0-16), \mathrm{A}^{\prime 3} \Delta_{u}(v=0-11), \mathrm{A}^{3} \Sigma_{u}^{+}(v=0-10)$ of $\mathrm{O}_{2}$. The quenching rate coefficients for singlet $a^{1} \Delta_{g}(v \geq 1)$ and $b^{1} \Sigma_{g}^{+}(v \geq 1)$ states and Herzberg states in the collisions $\mathrm{O}_{2}^{*}-\mathrm{O}_{2}$ and $\mathrm{O}_{2}^{*}-\mathrm{N}_{2}$ are taken according to results of the calculation by Kirillov (2008b) and described in the Sect. 2 .

We assume the main contribution in the excitation of Herzberg $c^{1} \Sigma_{u}^{-}, \mathrm{A}^{\prime 3} \Delta_{u}, \mathrm{~A}^{3} \Sigma_{u}^{+}$states by auroral electrons is from the Herzberg pseudocontinuum (Schulz and Dowell,
1962; Wakiya, 1978; Shyn and Sweeney, 2000). Therefore, it is proposed that the excitation rates of vibrational levels of the states are proportional to Franck-Condon factors, but the sums of the factors for every state is far less than 1 .

To calculate the population $N_{v}^{Y}$ of the $v$-th vibrational level of the $Y$-th electronic state we need a system of steadystate equations for all considered vibrational levels of $a^{1} \Delta_{g}$, $b^{1} \Sigma_{g}^{+}, c^{1} \Sigma_{u}^{-}, \mathrm{A}^{\prime 3} \Delta_{u}, \mathrm{~A}^{3} \Sigma_{u}^{+}$states. So we used in our calculations the following steady-state equations for the five electronic states of $\mathrm{O}_{2}$ :

$$
\begin{aligned}
& Q^{a} \cdot q_{v}^{a}+\sum_{v \prime} A_{v \prime v}^{A \prime a} \cdot N_{v^{\prime}}^{A \prime}+\sum_{Y=a, b, c, A^{\prime}, A ; v^{\prime}} k_{v^{\prime} v}^{* \mathrm{Ya}}\left[\mathrm{O}_{2}\right] \cdot N_{v^{\prime}}^{Y} \\
& +\sum_{Y=b, c, A \prime, A ; v^{\prime}} k_{v / v}^{\dagger \mathrm{Ya}}\left(\left[\mathrm{O}_{2}\right]+\left[\mathrm{N}_{2}\right]\right) \cdot N_{v^{\prime}}^{Y} \\
& =\left\{\sum_{v \prime} A_{v v^{\prime}}^{a X}+\sum_{v v^{\prime}} k_{v v^{\prime}}^{* a a}\left[\mathrm{O}_{2}\right]\right. \\
& \left.+\sum_{Y=X, b, c, A \prime, A ; v^{\prime}} k_{v v^{\prime}}^{\dagger a Y}\left(\left[\mathrm{O}_{2}\right]+\left[\mathrm{N}_{2}\right]\right)\right\} \cdot N_{v}^{a},
\end{aligned}
$$

$$
\begin{aligned}
& \mathrm{Q}^{\mathrm{b}} \cdot q_{v}^{b}+\sum_{Y=b, c, A \prime, A ; v^{\prime}} k_{v \prime v}^{* Y b}\left[\mathrm{O}_{2}\right] \cdot N_{v^{\prime}}^{Y} \\
& +\sum_{Y=a, c, A A^{\prime}, A ; v^{\prime}} k_{v \prime v}^{\dagger Y b}\left(\left[\mathrm{O}_{2}\right]+\left[N_{2}\right]\right) \cdot N_{v^{\prime}}^{Y} \\
& =\left\{\sum_{v \prime} A_{v v^{\prime}}^{b X}+\sum_{Y=a, b ; v^{\prime}} k_{v v^{\prime}}^{* b Y}\left[\mathrm{O}_{2}\right]\right. \\
& \left.+\sum_{Y=X, a, c, A, A ; v^{\prime}} k_{v v^{\prime}}^{\dagger b Y}\left(\left[\mathrm{O}_{2}\right]+\left[\mathrm{N}_{2}\right]\right)\right\} \cdot N_{v}^{b},
\end{aligned}
$$

$$
\begin{aligned}
& \mathrm{Q}^{\mathrm{c}} \cdot q_{v}^{c}+\sum_{Y=c, A \prime, A ; v^{\prime}} k_{v \prime v}^{* Y c}\left[\mathrm{O}_{2}\right] \cdot N_{v \prime}^{Y} \\
& +\sum_{Y=a, b, A \prime, A ; v^{\prime}} k_{v \prime v}^{\dagger Y c}\left(\left[\mathrm{O}_{2}\right]+\left[\mathrm{N}_{2}\right]\right) \cdot N_{v \prime}^{Y} \\
& +\sum_{v \prime} k_{v \prime v}^{* N 2 c}\left[\mathrm{O}_{2}\right] \cdot\left[\mathrm{N}_{2}\left(\mathrm{~A}^{3} \Sigma_{u}^{+}, v^{\prime}\right)\right]=\left\{\sum_{v \prime} A_{v v^{\prime}}^{c X}\right. \\
& +\sum_{Y=a, b, c, A \prime, A ; v \prime} k_{v v^{\prime}}^{* c Y}\left[\mathrm{O}_{2}\right] \\
& \left.\sum_{Y=X, a, b, A \prime, A ; v^{\prime}} k_{v v^{\prime}}^{\dagger c Y}\left(\left[\mathrm{O}_{2}\right]+\left[\mathrm{N}_{2}\right]\right)\right\} \cdot N_{v}^{c},
\end{aligned}
$$

$$
\begin{aligned}
& \mathrm{Q}^{\mathrm{A} \prime} \cdot q_{v}^{A \prime}+\sum_{Y=c, A \prime, A ; v \prime} k_{v \prime v}^{* Y A^{\prime}}\left[\mathrm{O}_{2}\right] \cdot N_{v^{\prime}}^{Y} \\
& +\sum_{Y=a, b, c, A ; v^{\prime}} k_{v \prime v}^{\dagger \mathrm{YA}^{\prime}}\left(\left[\mathrm{O}_{2}\right]+\left[\mathrm{N}_{2}\right]\right) \cdot N_{v^{\prime}}^{Y} \\
& \sum_{v \prime} k_{v \prime v}^{* \mathrm{~N}^{\prime} \mathrm{A}^{\prime}}\left[\mathrm{O}_{2}\right] \cdot\left[\mathrm{N}_{2}\left(\mathrm{~A}^{3} \Sigma_{u}^{+}, v^{\prime}\right)\right]=\left\{\sum_{v \prime} A_{v v v^{\prime}}^{A \prime X}+\sum_{v \prime} A_{v v^{\prime}}^{A \prime a}\right. \\
& +\sum_{Y=a, b, c, A \prime, A ; v^{\prime}} k_{v v^{\prime}}^{* A \prime Y}\left[\mathrm{O}_{2}\right] \\
& \left.+\sum_{Y=X, a, b, c, A ; v^{\prime}} k_{v v^{\prime}}^{\dagger A / Y}\left(\left[\mathrm{O}_{2}\right]+\left[\mathrm{N}_{2}\right]\right)\right\} \cdot N_{v}^{A \prime},
\end{aligned}
$$




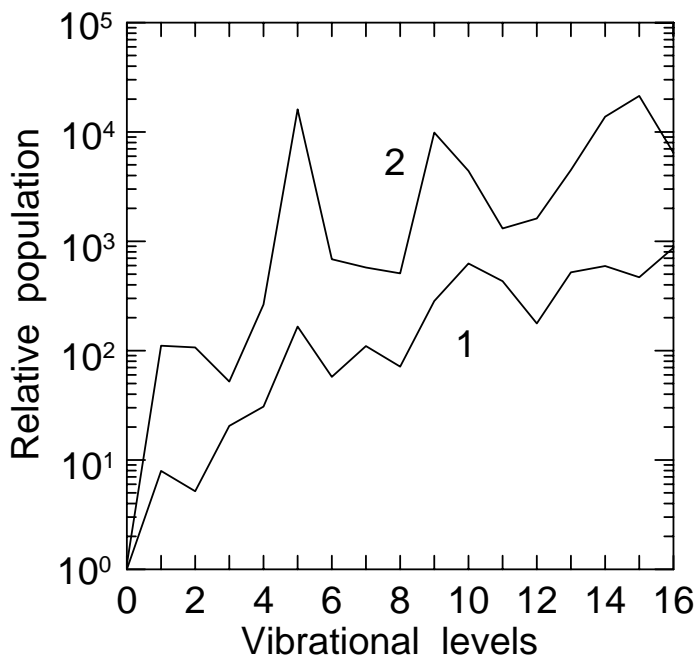

Fig. 11. The calculated relative vibrational populations of the $c^{1} \Sigma_{u}^{-}$ state of $\mathrm{O}_{2}$ at the altitude of $80 \mathrm{~km}: 1$ and 2 - without and with the contribution of the process $(4 \mathrm{~b})$.

$$
\begin{aligned}
& \mathrm{Q}^{\mathrm{A}} \cdot q_{v}^{A}+\sum_{Y=c, A \prime, A ; v \prime} k_{v / v}^{* \mathrm{YA}_{0}}\left[\mathrm{O}_{2}\right] \cdot N_{v^{\prime}}^{Y} \\
& +\sum_{Y=a, b, c, A \prime ; v^{\prime}} k_{v \prime v}^{\dagger \mathrm{YA}}\left(\left[\mathrm{O}_{2}\right]+\left[\mathrm{N}_{2}\right]\right) \cdot N_{v \prime}^{Y} \\
& +\sum_{v \prime} k_{v \prime v}^{* \mathrm{~N} 2 \mathrm{~A}}\left[\mathrm{O}_{2}\right] \cdot\left[\mathrm{N}_{2}\left(\mathrm{~A}^{3} \Sigma_{u}^{+}, v^{\prime}\right)\right]=\left\{\sum_{v \prime} A_{v v^{\prime}}^{\mathrm{AX}}\right. \\
& +\sum_{Y=a, b, c, A, A ;, v^{\prime}} k_{v v^{\prime}}^{* \mathrm{AY}}\left[\mathrm{O}_{2}\right] \\
& \left.+\sum_{Y=X, a, b, c, A \prime ; v^{\prime}} k_{v v^{\prime}}^{\dagger \mathrm{AY}}\left(\left[\mathrm{O}_{2}\right]+\left[\mathrm{N}_{2}\right]\right)\right\} \cdot N_{v}^{A},
\end{aligned}
$$

where $\mathrm{Q}^{\mathrm{Y}}$ is the production rate of the $\mathrm{Y}$-th state by auroral electrons (in $\mathrm{cm}^{-3} \mathrm{~s}^{-1}$ ), $q_{v}^{Y}$ is the Franck-Condon factor for the transition $\mathrm{X}^{3} \Sigma_{g}^{-}, v=0 \rightarrow \mathrm{Y}, v, \mathrm{~A}_{v v}^{\mathrm{YZ}}$ is the spontaneous transition probability for the transition $\mathrm{Y}, v \rightarrow \mathrm{Z}, v^{\prime}$, $k_{v v^{\prime}}^{* \mathrm{YZ}}$ and $k_{v v^{\prime}}^{\dagger \mathrm{YZ}}$ are the rate coefficients for intermolecular and intramolecular electron energy transfer processes with the quenching of $Y, v$ and the excitation of $Z, v^{\prime}$, respectively. As for $\mathrm{N}_{2}$ molecule we suggest to consider the rate of an intramolecular process independent on the kind of the colliders $\mathrm{O}_{2}$ or $\mathrm{N}_{2}$. Actually experimental results by Knutsen et al. (1994) and Copeland et al. (1996) shown in Figs. 1, 2, 4, 5 have indicated that the quenching rates on $\mathrm{N}_{2}$ molecules are somewhat smaller, but the difference is not so important in our consideration of the kinetics of electronically excited $\mathrm{O}_{2}$. Therefore, the sum of concentrations $\left[\mathrm{O}_{2}\right]+\left[\mathrm{N}_{2}\right]$ is included in steady-state Eqs. (10a-e) for contributions of intramolecular processes. Contributions of intermolecular electron energy transfer processes in collisions of $\mathrm{N}_{2}\left(\mathrm{~A}^{3} \Sigma_{u}^{+}, v\right)$ with $\mathrm{O}_{2}$ with the production of $\mathrm{O}_{2}\left(c^{1} \Sigma_{u}^{-}\right), \mathrm{O}_{2}\left(\mathrm{~A}^{\prime 3} \Delta_{u}\right), \mathrm{O}_{2}\left(\mathrm{~A}^{3} \Sigma_{u}^{+}\right)$ are included in the Eqs. (10c-e) and the rate coefficients of these interactions are denoted by $k_{v / v}^{* \mathrm{~N} 2 \mathrm{c}}, k_{v / v}^{* \mathrm{~N} 2 \mathrm{~A}}, k_{v / v}^{* \mathrm{~N} 2 \mathrm{~A}}$. Ap-

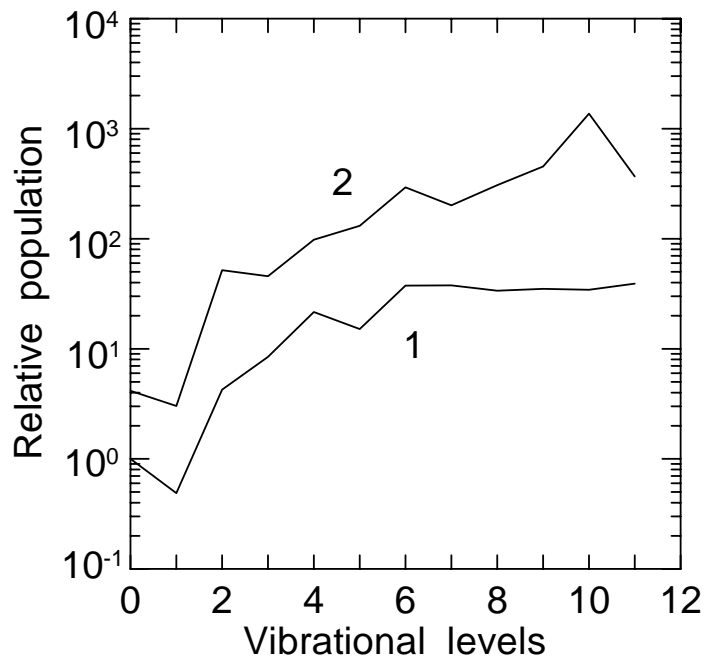

Fig. 12. The same as in Fig. 11 , but for the $\mathrm{A}^{\prime 3} \Delta_{u}$ state: 1 and $2-$ without and with the contribution of the process $(4 b)$.

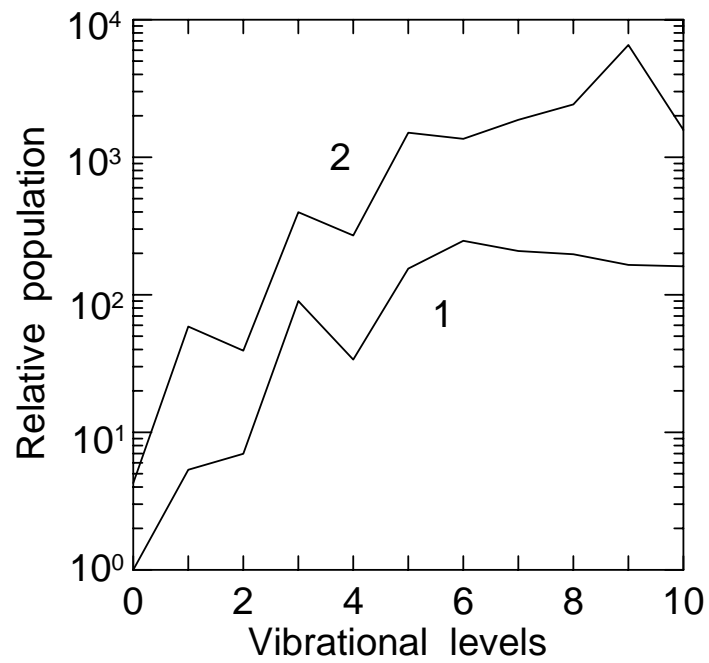

Fig. 13. The same as in Fig. 11, but for the $\mathrm{A}^{3} \Sigma_{u}^{+}$state: 1 and $2-$ without and with the contribution of the process $(4 b)$.

plied rate coefficients $k_{v}^{* \mathrm{YZ}}$ and $k_{v}^{\dagger \mathrm{YZ}}$ for intermolecular and intramolecular processes in the Eqs. (10c-e) for Herzberg states are shown in Tables $1-3$. The rate coefficients $k_{v}^{* \mathrm{YZ}}$ and $k_{v}^{\dagger \mathrm{YZ}}$ mean sums of $k_{v v^{\prime}}^{* \mathrm{YZ}}$ and $k_{v v^{\prime}}^{\dagger \mathrm{YZ}}$ on quantum number $v^{\prime}$.

Here we consider the processes

$\mathrm{O}_{2}\left(a^{1}, v=0\right)+\mathrm{O}_{2}\left(\mathrm{X}^{3}, v=0\right) \rightarrow \mathrm{O}_{2}\left(\mathrm{X}^{3}, v^{\prime \prime}=5\right)+\mathrm{O}_{2}\left(\mathrm{X}^{3}, v=0\right)$

and

$\mathrm{O}_{2}\left(b^{1}, v=0\right)+\mathrm{N}_{2}\left(\mathrm{X}^{1}, v=0\right) \rightarrow \mathrm{O}_{2}\left(a^{1}, v^{\prime \prime}=3\right)+\mathrm{N}_{2}\left(\mathrm{X}^{1}, v=0\right)$ 
Table 1. Applied rate coefficients in Eq. (10c).

\begin{tabular}{cccccc}
\hline$v$ & $k_{v}^{* c a}$ & $k_{v}^{* c b}$ & $k_{v}^{* c c}$ & $k_{v}^{* c A \prime}$ & $k_{v}^{* c A}$ \\
\hline 0 & $2.3(-14)$ & $2.8(-13)$ & - & - & - \\
1 & $4.1(-13)$ & $5.2(-14)$ & - & - & - \\
2 & $5.3(-14)$ & $1.7(-12)$ & - & - & - \\
3 & $1.8(-12)$ & $2.4(-15)$ & - & - & - \\
4 & $1.1(-12)$ & $4.1(-13)$ & - & - & - \\
5 & $2.2(-14)$ & $3.8(-14)$ & - & - & - \\
6 & $4.2(-12)$ & $1.7(-13)$ & - & $1.0(-16)$ & - \\
7 & $3.0(-14)$ & $8.3(-14)$ & $1.6(-16)$ & $7.2(-16)$ & - \\
8 & $4.9(-13)$ & $2.0(-13)$ & $1.1(-15)$ & $1.1(-15)$ & $2.5(-16)$ \\
9 & $4.2(-14)$ & $1.6(-14)$ & $2.1(-15)$ & $1.0(-15)$ & $2.5(-16)$ \\
10 & $1.0(-13)$ & $5.7(-13)$ & $4.2(-15)$ & $7.6(-15)$ & $4.8(-16)$ \\
11 & $4.4(-14)$ & $1.4(-14)$ & $3.2(-15)$ & $4.0(-15)$ & $8.6(-16)$ \\
12 & $1.2(-13)$ & $2.7(-13)$ & $2.2(-15)$ & $2.0(-14)$ & $2.5(-15)$ \\
13 & $1.6(-13)$ & $2.6(-13)$ & $8.1(-15)$ & $1.9(-14)$ & $5.7(-15)$ \\
14 & $4.1(-14)$ & $2.1(-14)$ & $6.4(-15)$ & $1.5(-14)$ & $2.3(-15)$ \\
15 & $3.9(-14)$ & $1.8(-14)$ & $6.0(-15)$ & $3.3(-14)$ & $9.3(-15)$ \\
16 & $1.1(-12)$ & $2.8(-13)$ & $1.1(-14)$ & $6.2(-14)$ & $7.6(-15)$ \\
\hline$v$ & $k_{v}^{\dagger c X}$ & $k_{v}^{\dagger c c}$ & $k_{v}^{\dagger c b}$ & $k_{v}^{\dagger c A \prime}$ & $k_{v}^{\dagger c A}$ \\
\hline 0 & - & $3.1(-16)$ & $2.9(-16)$ & - & - \\
1 & $2.6(-16)$ & $2.6(-14)$ & $1.8(-15)$ & - & - \\
2 & $7.0(-16)$ & $2.9(-14)$ & $2.2(-14)$ & $2.3(-16)$ & - \\
3 & $3.6(-14)$ & $3.1(-13)$ & $2.6(-13)$ & $2.0(-16)$ & $2.4(-16)$ \\
4 & $2.9(-13)$ & $1.1(-13)$ & $1.5(-12)$ & $1.6(-16)$ & $2.5(-16)$ \\
5 & $1.6(-13)$ & $2.6(-13)$ & $3.9(-12)$ & $3.7(-16)$ & $1.7(-16)$ \\
6 & $2.7(-13)$ & $8.8(-13)$ & $2.3(-12)$ & $1.6(-15)$ & $1.7(-16)$ \\
7 & $2.4(-12)$ & $3.0(-12)$ & $1.2(-12)$ & $6.9(-15)$ & $6.9(-16)$ \\
8 & $1.4(-11)$ & $2.1(-12)$ & $5.6(-13)$ & $7.6(-15)$ & $3.8(-15)$ \\
9 & $4.1(-12)$ & $4.4(-12)$ & $1.7(-13)$ & $2.4(-15)$ & $2.7(-15)$ \\
10 & $1.8(-13)$ & $9.0(-13)$ & $2.3(-13)$ & $1.1(-15)$ & $8.4(-16)$ \\
11 & $1.2(-12)$ & $6.2(-13)$ & $1.7(-12)$ & $2.5(-15)$ & $7.0(-16)$ \\
12 & $9.8(-12)$ & $1.1(-12)$ & $3.7(-12)$ & $1.2(-14)$ & $2.7(-15)$ \\
13 & $1.0(-12)$ & $1.3(-12)$ & $2.2(-12)$ & $1.6(-14)$ & $1.0(-15)$ \\
14 & $1.2(-12)$ & $4.9(-12)$ & $4.0(-13)$ & $2.1(-14)$ & $1.4(-15)$ \\
15 & $5.6(-12)$ & $1.1(-12)$ & $9.5(-13)$ & $7.0(-15)$ & $3.0(-15)$ \\
16 & $3.2(-13)$ & $1.0(-12)$ & $3.4(-13)$ & $4.5(-13)$ & $2.6(-14)$ \\
\hline & & & & &
\end{tabular}

are main quenching mechanisms of these levels with the rate coefficients $k_{11}=2 \times 10^{-18} \mathrm{~cm}^{3} \mathrm{~s}^{-1}$ and $k_{12}=2 \times 10^{-15} \mathrm{~cm}^{3} \mathrm{~s}^{-1}$ (Morozov and Temchin, 1990). The interaction of $\mathrm{O}_{2}\left(b^{1} \Sigma_{g}^{+}, v=0\right)$ with $\mathrm{O}_{2}$ is neglected since the corresponding rate coefficient is sufficiently less than $k_{12}$ (Kirillov, 2004b) and the concentration of $\mathrm{O}_{2}$ is about one order less than $\left[\mathrm{N}_{2}\right]$ at the altitudes of lower thermosphere and mesosphere.

Calculated relative vibrational populations of the $c^{1} \Sigma_{u}^{-}$, $\mathrm{A}^{\prime 3} \Delta_{u}, \mathrm{~A}^{3} \Sigma_{u}^{+}$states of $\mathrm{O}_{2}$ at the altitude of $80 \mathrm{~km}$ are presented in Figs. 11-13. Similar populations at the altitude of $100 \mathrm{~km}$ are not shown here as far as there is not any principal change in the shapes of the curves. Results of the calculation are given in Figs. 11-13 for two cases. At first we have made the calculation without the inclusion of electronic energy transfer processes (4b). In the second instance the
Table 2. Applied rate coefficients in Eq. (10d).

\begin{tabular}{|c|c|c|c|c|c|}
\hline$v$ & $k_{v}^{* A^{\prime} a}$ & $k_{v}^{* A \prime b}$ & $k_{v}^{* A \prime c}$ & $k_{v}^{* A^{\prime} A^{\prime}}$ & $k_{v}^{* A \prime A}$ \\
\hline 0 & $1.1(-15)$ & $9.6(-14)$ & - & - & - \\
\hline 1 & $1.0(-14)$ & $1.5(-$ & - & - & - \\
\hline 2 & $5.3(-13)$ & $3.8(-14)$ & - & - & - \\
\hline 3 & $1.1(-12)$ & $3.5(-13)$ & - & - & - \\
\hline 4 & $1.8(-13)$ & $7.7(-15)$ & $1.7(-16)$ & - & - \\
\hline 5 & $1.9(-12)$ & $1.6(-$ & $8.6(-16)$ & - & - \\
\hline 6 & $7.6(-14)$ & $7.7(-14)$ & $1.7(-15)$ & $1.5(-16)$ & $1.9(-16)$ \\
\hline 7 & $3.4(-13)$ & $1.1(-13)$ & $1.9(-15)$ & $9.2(-16)$ & $5.2(-16)$ \\
\hline 8 & $1.1(-12)$ & $9.8(-14)$ & $4.3(-15)$ & $6.8(-15)$ & $1.7(-15)$ \\
\hline 9 & $8.3(-14)$ & $3.0(-13)$ & $7.7(-15)$ & $4.2(-14)$ & $5.5(-15)$ \\
\hline 10 & $2.2(-13)$ & $9.9(-15)$ & $1.8(-14)$ & $8.7(-15)$ & $5.2(-15)$ \\
\hline 11 & $6.3(-14)$ & $5.6(-13)$ & $2.4(-14)$ & $1.9(-14)$ & $6.8(-15)$ \\
\hline$v$ & $k_{v}^{\dagger A^{\prime} X}$ & $k_{v}^{\dagger A^{\prime} a}$ & $k_{v}^{\dagger A / b}$ & $k_{v}^{\dagger A / c}$ & $k_{v}^{\dagger A^{\prime} A}$ \\
\hline 0 & - & $1.3(-15)$ & - & $1.3(-16)$ & $4.9(-14)$ \\
\hline 1 & $2.6(-16)$ & $8.8(-1)$ & $1.2(-16)$ & $1.6(-16)$ & $3.5(-13)$ \\
\hline 2 & - & $3.3(-16)$ & $6.7(-16)$ & $1.4(-16)$ & $8.3(-13)$ \\
\hline 3 & - & $1.2(-14)$ & $1.2(-15)$ & $2.1(-16)$ & $1.6(-12)$ \\
\hline 4 & $2.3(-15)$ & $5.1(-14)$ & $8.4(-15)$ & $9.5(-16)$ & $2.7(-12)$ \\
\hline 5 & $6.7(-14)$ & $4.7(-13)$ & $2.8(-14)$ & $1.7(-15)$ & $4.5(-12)$ \\
\hline 6 & $5.1(-13)$ & $2.5(-13)$ & $1.4(-13)$ & $8.9(-16)$ & $7.4(-12)$ \\
\hline 7 & $1.4(-12)$ & $2.3(-12)$ & $3.0(-13)$ & $6.2(-16)$ & $1.2(-11)$ \\
\hline 8 & $2.9(-12)$ & $1.6(-12)$ & $1.7(-12)$ & $2.0(-15)$ & $1.9(-11)$ \\
\hline 9 & $5.3(-12)$ & $4.1(-12)$ & $2.1(-12)$ & $4.1(-15)$ & $3.0(-11)$ \\
\hline 10 & $1.0(-11)$ & $5.4(-12)$ & $2.6(-12)$ & $8.1(-15)$ & $2.6(-11)$ \\
\hline 11 & $2.2(-12)$ & $3.1(-12)$ & $2.6(-12)$ & $8.4(-14)$ & $2.2(-11)$ \\
\hline
\end{tabular}

contribution of the processes (4b) is taken into consideration. The normalising of presented populations is made on the populations of vibrational level $\mathrm{v}=0$ for the first instance. Figures 11-13 indicate obviously that these intermolecular processes are dominant in the population of Herzberg states at altitudes of lower thermosphere and mesosphere during auroral electron precipitation and the inclusion of the processes (4b) is very important in the study of electronic kinetics of $\mathrm{O}_{2}$.

The calculations for the $a^{1} \Delta_{g}$ and $b^{1} \Sigma_{g}^{+}$states have shown that the population of the $v=0$ level is much greater than populations of other levels in both cases. This fact can be explained by very high rates of the (6) process with $\gamma=a^{1}$, $b^{1}$ at $v=0$ and intermolecular processes

$\mathrm{O}_{2}\left(a^{1}, v\right)+\mathrm{O}_{2}\left(\mathrm{X}^{3}, v=0\right) \rightarrow \mathrm{O}_{2}\left(\mathrm{X}^{3}, v^{\prime \prime}\right)+\mathrm{O}_{2}\left(a^{1}, v^{\prime}=0\right),(13 \mathrm{a})$

$\mathrm{O}_{2}\left(b^{1}, v\right)+\mathrm{O}_{2}\left(\mathrm{X}^{3}, v=0\right) \rightarrow \mathrm{O}_{2}\left(\mathrm{X}^{3}, v^{\prime \prime}\right)+\mathrm{O}_{2}\left(b^{1}, v^{\prime}=0\right) .(13 \mathrm{~b})$

Calculated vibrational populations of the $a^{1} \Delta_{g}(v \geq 1)$ and $b^{1} \Sigma_{g}^{+}(v \geq 1)$ states of $\mathrm{O}_{2}$ at the altitude $80 \mathrm{~km}$ are plotted in Figs. 14 and 15, respectively. As in the case of Herzberg states our results are presented for two cases of the absence and inclusion of the contribution of the processes (4b) in the calculation. The normalising is made on the population of 
Table 3. Applied rate coefficients in Eq. (10e).

\begin{tabular}{cccccc}
\hline$v$ & $k_{v}^{* A a}$ & $k_{v}^{* A b}$ & $k_{v}^{* A c}$ & $k_{v}^{* A A^{\prime}}$ & $k_{v}^{* A A}$ \\
\hline 0 & $3.9(-15)$ & $1.9(-14)$ & - & - & - \\
1 & $3.6(-13)$ & $1.0(-13)$ & - & - & - \\
2 & $6.2(-14)$ & $3.9(-12)$ & - & - & - \\
3 & $3.8(-13)$ & $2.1(-14)$ & - & - & - \\
4 & $7.5(-12)$ & $2.7(-13)$ & $2.8(-16)$ & - & - \\
5 & $1.8(-13)$ & $2.4(-13)$ & $5.9(-16)$ & $2.6(-16)$ & - \\
6 & $8.5(-15)$ & $6.1(-14)$ & $8.9(-16)$ & $1.5(-15)$ & - \\
7 & $7.1(-13)$ & $2.2(-13)$ & $2.0(-15)$ & $6.4(-15)$ & $3.7(-16)$ \\
8 & $9.9(-14)$ & $1.3(-13)$ & $5.2(-15)$ & $1.9(-14)$ & $1.4(-15)$ \\
9 & $8.5(-14)$ & $1.7(-14)$ & $1.0(-14)$ & $1.6(-14)$ & $1.3(-15)$ \\
10 & $8.8(-13)$ & $9.8(-14)$ & $1.9(-14)$ & $2.0(-14)$ & $1.9(-15)$ \\
\hline \multirow{2}{*}{$v$} & $k_{v}^{\dagger A X}$ & $k_{v}^{\dagger A a}$ & $k_{v}^{\dagger A b}$ & $k_{v}^{\dagger A c}$ & $k_{v}^{\dagger A A \prime}$ \\
\hline 0 & - & $2.9(-15)$ & $1.1(-16)$ & $2.4(-13)$ & $2.2(-12)$ \\
1 & $2.0(-15)$ & $6.7(-15)$ & $2.0(-16)$ & $8.6(-13)$ & $2.9(-12)$ \\
2 & $4.8(-16)$ & $4.1(-15)$ & $3.0(-16)$ & $3.9(-13)$ & $4.0(-12)$ \\
3 & $3.8(-15)$ & $9.6(-14)$ & $2.5(-15)$ & $4.0(-13)$ & $5.8(-12)$ \\
4 & $3.3(-14)$ & $1.8(-13)$ & $5.3(-15)$ & $2.8(-13)$ & $8.7(-12)$ \\
5 & $1.2(-13)$ & $2.2(-13)$ & $3.1(-14)$ & $1.7(-12)$ & $1.4(-11)$ \\
6 & $2.4(-13)$ & $1.6(-12)$ & $6.4(-14)$ & $2.2(-13)$ & $2.3(-11)$ \\
7 & $9.1(-13)$ & $9.5(-13)$ & $8.8(-13)$ & $2.4(-13)$ & $3.8(-11)$ \\
8 & $2.9(-12)$ & $3.6(-12)$ & $9.8(-13)$ & $7.9(-13)$ & $6.6(-11)$ \\
9 & $9.6(-12)$ & $4.2(-12)$ & $1.2(-12)$ & $8.4(-13)$ & $6.6(-11)$ \\
10 & $1.4(-12)$ & $2.6(-12)$ & $1.1(-12)$ & $1.9(-12)$ & $6.8(-11)$ \\
\hline & & & & &
\end{tabular}

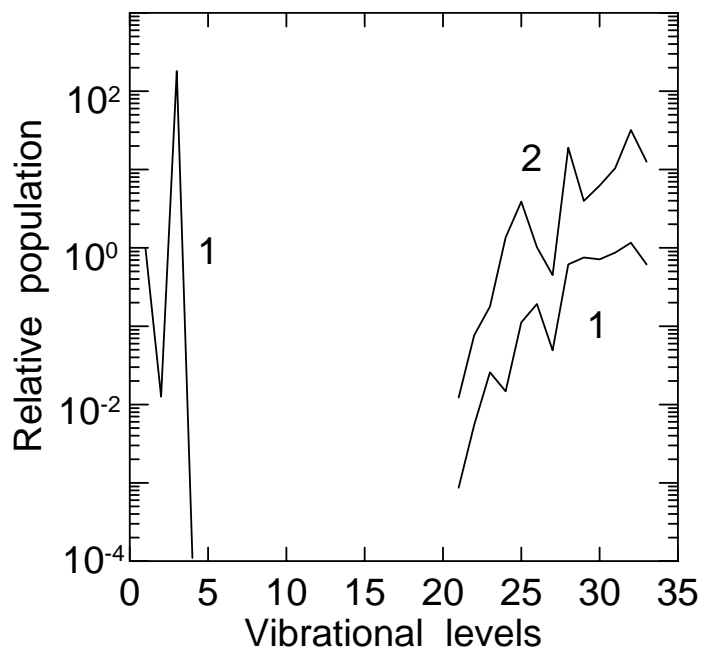

Fig. 14. The same as in Fig. 11, but for the $a^{1} \Delta g$ state: 1 and $2-$ without and with the contribution of processes (4b).

vibrational level $\mathrm{v}=1$ without the consideration of the processes (4b). It is seen from Figs. 14 and 15 that there is an influence of these intermolecular processes on the population of high vibrational levels of singlet states at the altitudes of auroral lower thermosphere and mesosphere. This is related with cascades from Herzberg states to the $a^{1} \Delta_{g}$ and $b^{1} \Sigma_{g}^{+}$ states by radiational and collisional electron energy transfers.

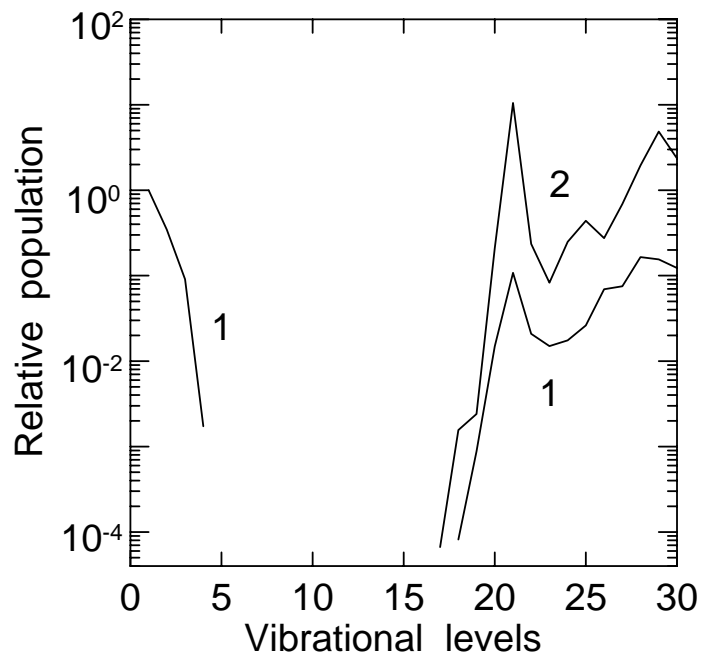

Fig. 15. The same as in Fig. 11, but for the $b^{1} \Sigma_{g}^{+}$state: 1 and $2-$ without and with the contribution of processes (4b).

The calculation has shown that the influence of intermolecular processes $(4 \mathrm{~b})$ on the populations of lowest vibrational levels of these singlet states is negligible. Obtained populations of lowest vibrational levels are explained by the excitation mainly in the (6) process. Considerable increase of the population for the $\mathrm{v}=3$ level of the $a^{1} \Delta_{g}$ state is related with intramolecular electron energy transfer process (12).

Emissions from Herzberg states of $\mathrm{O}_{2}$ are observed in the nightglow of the atmosphere. The $\mathrm{A}^{3} \Sigma_{u}^{+}-\mathrm{X}^{3} \Sigma_{g}^{-}$electronic transition (Herzberg I bands) is the dominant emission from the Herzberg states in the earth's atmosphere, but the $c^{1} \Sigma_{u}^{-}-\mathrm{X}^{3} \Sigma_{g}^{-}$(Herzberg II bands) and $\mathrm{A}^{\prime 3} \Delta_{u}-a^{1} \Delta_{g}$ (Chamberlain bands) transitions have also been identified (Broadfoot and Kendall, 1968; Slanger and Huestis, 1981). The emissions are located in the ultraviolet and blue regions of the spectrum. Since the bands of First Negative Group (1NG) of $\mathrm{N}_{2}^{+}$and of VK and Second Positive Group (2PG) of $\mathrm{N}_{2}$ are very intensive in the regions of the spectrum of an aurora (see Figs. 4.2 and 4.3 of Vallance Jones, 1974), so any registration of the $\mathrm{O}_{2}$ emissions in auroral observations seems problematic.

Vallance Jones (1974) (Tables 4.15 and 4.16) and Henriksen and Sivjee (1990) in their observations of auroral ionosphere have measured intensities of bands resulting from the transitions from low vibrational levels of the $a^{1} \Delta_{g}(v=0-1)$ and $b^{1} \Sigma_{g}^{+}(v=0-5)$ states. The emissions are located in infrared and near infrared regions of the spectrum of the aurora. The atmospheric bands of $\mathrm{O}_{2}$ (transition $b^{1} \Sigma_{g}^{+}-\mathrm{X}^{3} \Sigma_{g}^{-}$) are overlapped with the bands of Meinel system of $\mathrm{N}_{2}^{+}$and of 1PG of $\mathrm{N}_{2}$ (see Figs. 4.2 and 4.3 of Vallance Jones, 1974), so an observed auroral spectrum needs a correct synthetic analysis.

Therefore, we consider our conclusion about the principal role of the $\mathrm{N}_{2}\left(\mathrm{~A}^{3} \Sigma_{u}^{+}\right)+\mathrm{O}_{2}$ interaction in the kinetics of five 
electronic states of $\mathrm{O}_{2}$ at the considered altitudes in auroral ionosphere as preliminary. Unfortunately, available experimental data from measurements of the $\mathrm{O}_{2}$ bands in auroras do not allow to faithfully reproduce the mechanisms of the electronic excitation of molecular oxygen at the altitudes of high-latitude lower thermosphere and mesosphere. May be studies related with laboratory investigations of a discharge in the mixture of $\mathrm{N}_{2}-\mathrm{O}_{2}$ shall help in the understanding of the role of these intermolecular processes in electronic kinetics of $\mathrm{O}_{2}$.

\section{Conclusions}

Here we presented the results of our calculation of the quenching rate coefficients for Herzberg states of molecular oxygen and three triplet states of molecular nitrogen in collisions with $\mathrm{O}_{2}$ and $\mathrm{N}_{2}$ molecules comparing the contributions of intamolecular and intermolecular electron energy transfer processes in the quenching. The calculated rate coefficients are applied in the study of electronic kinetics of $\mathrm{N}_{2}$ and $\mathrm{O}_{2}$ at the altitudes of high-latitude lower thermosphere and mesosphere.

The main results of these calculations are as follows.

1. It is obtained that both intramolecular and intermolecular electron energy transfer processes are important in the quenching of the $c^{1} \Sigma_{u}^{-}, \mathrm{A}^{\prime 3} \Delta_{u}, \mathrm{~A}^{3} \Sigma_{u}^{+}$states of molecular oxygen and of the $\mathrm{A}^{3} \Sigma_{u}^{+}, \mathrm{W}^{3} \Delta_{u}, \mathrm{~B}^{\prime 3} \Sigma_{u}^{-}$ states of molecular nitrogen in the collisions with $\mathrm{N}_{2}$ and $\mathrm{O}_{2}$ molecules. Results of the calculation of total quenching rate coefficients have shown a good agreement with available experimental data.

2. The study of vibrational populations of electronically excited $\mathrm{N}_{2}$ at the altitudes of high-latitude lower thermosphere and mesosphere during auroral electron precipitation has shown that collisional processes cause an enhancement in the population of high vibrational levels of the $\mathrm{A}^{3} \Sigma_{u}^{+}$state with the rise in atmospheric density. The behaviour of this state correlates with the behaviour of the $\mathrm{B}^{3} \Pi_{g}$ state considered by Benesch $(1981,1983)$, Morrill and Benesch (1996), Kirillov (2008a).

3. It is obtained preliminary that molecular collisions of metastable nitrogen molecules $\mathrm{N}_{2}\left(\mathrm{~A}^{3} \Sigma_{u}^{+}\right)$with $\mathrm{O}_{2}$ molecules dominate in electronic excitation of molecular oxygen $\mathrm{O}_{2}\left(\mathrm{X}^{3} \Sigma_{g}^{-}\right)$to Herzberg states $c^{1} \Sigma_{u}^{-}, \mathrm{A}^{\prime 3} \Delta_{u}$, $\mathrm{A}^{3} \Sigma_{u}^{+}$in auroral lower thermosphere and mesosphere. Similar estimations of vibrational populations for $a^{1} \Delta_{g}$ and $b^{1} \Sigma_{g}^{+}$singlet states have shown that there is the principal influence of the $\mathrm{N}_{2}\left(\mathrm{~A}^{3} \Sigma_{u}^{+}\right)+\mathrm{O}_{2}$ interaction on the populations of high vibrational levels of the states.

Acknowledgements. This research is supported by the Division of Physical Sciences of RAS (program "Plasma processes in the solar system"), by the Program of Presidium of RAS No16, by the grant 08-05-00226 of Russian Foundation for Basic Research (RFBR) and by Norwegian and Russian Upper Atmosphere Cooperation on Svalbard \#178911/S30 Research Council of Norway.

Topical Editor C. Jacobi thanks two anonymous referees for their help in evaluating this paper.

\section{References}

Bates, D. R.: Excitation and quenching of the oxygen bands in the nightglow, Planet. Space Sci., 36, 875-881, 1988.

Bates, D. R.: Oxygen band system transition arrays, Planet. Space Sci., 37, 881-887, 1989.

Benesch, W.: Mechanism for the auroral red lower border, J. Geophys. Res., 86, 9065-9072, 1981.

Benesch, W.: Intersystem collisional transfer of excitation in low altitude aurora, J. Chem. Phys., 78, 2978-2983, 1983.

Broadfoot, A. L. and Kendall, K. R.: The airglow spectrum, 300010000 A, J. Geophys. Res., 73, 426-428, 1968.

Campbell, L. and Brunger, M. J.: Electron impact contribution to infrared NO emissions in auroral conditions, Geophys. Res. Lett., 34, L22102, doi:10.1029/2007GL031743, 2007.

Campbell, L., Cartwright, D. C., and Brunger, M. J.: Role of excited $\mathrm{N}_{2}$ in the production of nitric oxide, J. Geophys. Res., 112, A08303, doi:10.1029/2007JA012337, 2007.

Copeland, R. A., Knutsen, K., and Slanger, T. G.: Using laserinduced fluorescence to study molecules of atmospheric importance, Proceedings of the International Conference on Lasers '93, STS Press, McLean, 318-325, 1994.

Copeland, R. A., Knutsen, K., Onishi, M. E., and Yalcin, T.: Collisional removal of $\mathrm{O}_{2}\left(\mathrm{c}^{1} \Sigma_{u}^{-}, \mathrm{v}=9\right)$ by $\mathrm{O}_{2}, \mathrm{~N}_{2}$, and $\mathrm{He}$, J. Chem. Phys., 105, 10349-10355, 1996.

De Benedictis, S. and Dilecce, G.: Rate constants for deactivation of $\mathrm{N}_{2}$ (A) $v=2-7$ by $\mathrm{O}, \mathrm{O}_{2}$, and NO, J. Chem. Phys., 107, 62196229, 1997.

Dreyer, J. W. and Perner, D.: Deactivation of $\mathrm{N}_{2}\left(\mathrm{~A}^{3} \Sigma_{u}^{+}, v=0-7\right)$ by ground state nitrogen, ethane, and ethylene measured by kinetic absorption spectroscopy, J. Chem. Phys., 58, 1195-1201, 1973.

Dreyer, J. W., Perner, D., and Roy, C. R.: Rate constants for the quenching of $\mathrm{N}_{2}\left(\mathrm{~A}^{3} \Sigma_{u}^{+}, \mathrm{v}_{A}=0-8\right)$ by $\mathrm{CO}, \mathrm{CO}_{2}, \mathrm{NH}_{3}, \mathrm{NO}$, and $\mathrm{O}_{2}$, J. Chem. Phys., 61, 3164-3169, 1974.

Eastes, R. W. and Sharp, W. E.: Rocket-borne spectroscopic measurements in the ultraviolet aurora: The Lyman-Birge-Hopfield bands, J. Geophys. Res., 92, 10095-10100, 1987.

Gattinger, R. L. and Vallance Jones, A.: Observations and interpretation of spectra and rapid time variations of type-B red aurora, Planet. Space Sci., 27, 169-181, 1979.

Gattinger, R. L., Harris, F. R., and Vallance Jones, A.: The height, spectrum and mechanism of type-B red aurora and its bearing on the excitation of $\mathrm{O}\left({ }^{1} \mathrm{~S}\right)$ in aurora, Planet. Space Sci., 33, 207221, 1985.

Gilmore, F. R., Laher, R. R., and Espy, P. J.: Franck-Condon factors, r-centroids, electronic transition moments, and Einstein coefficients for many nitrogen and oxygen band systems, J. Phys. Chem. Ref. Data, 21, 1005-1107, 1992.

Guerra, V., Sa, P. A., and Loureiro, J.: Nitrogen pink afterglow: the mystery continues, J. Phys.: Conf. Ser., 63, 012007, 2007.

Henriksen, K. and Sivjee, G. D.: Auroral vibrational population of the $\mathrm{O}_{2}\left(b^{1} \Sigma_{g}^{+}, v^{\prime}\right)$ levels, Planet. Space Sci., 38, 835-840, 1990. 
Kamaratos, E.: Orange flame from active nitrogen and oxygen in the absence of a metal catalyst resulting from collisional intersystem crossing into $\mathrm{N}_{2}\left(\mathrm{~B}^{3} \Pi_{g}\right)$, J. Phys. Chem., 101, 2040-2044, 1997.

Kamaratos, E.: Active nitrogen and oxygen: Enhanced emissions and chemical reactions, Chem. Phys., 323, 271-294, 2006.

Kamaratos, E.: Comment on "Plasma chemistry of sprite streamers" by D. D. Sentman, H. C. Stenbaek-Nielsen, M. G. McHarg, and J. C. Morrill, J. Geophys. Res., 114, D08109, doi:10.1029/2008JD011196, 2009.

Kirillov, A. S.: Application of Landau-Zener and Rosen-Zener approximations to calculate rates of electron energy transfer processes, Adv. Space Res., 33, 993-997, 2004a.

Kirillov, A. S.: Calculation of rate coefficients of electron energy transfer processes for molecular nitrogen and molecular oxygen, Adv. Space Res., 33, 998-1004, 2004b.

Kirillov, A. S.: Electronically excited molecular nitrogen and molecular oxygen in the high-latitude upper atmosphere, Ann. Geophys., 26, 1159-1169, 2008a, http://www.ann-geophys.net/26/1159/2008/.

Kirillov, A. S.: The study of intermolecular energy transfers in electronic energy quenching for molecular collisions $\mathrm{N}_{2}-\mathrm{N}_{2}, \mathrm{~N}_{2}-\mathrm{O}_{2}$, $\mathrm{O}_{2}-\mathrm{O}_{2}$, Ann. Geophys., 26, 1149-1157, 2008b, http://www.ann-geophys.net/26/1149/2008/.

Knutsen, K., Dyer, M. J., and Copeland, R. A.: Laser doubleresonance study of the collisional removal of $\mathrm{O}_{2}\left(\mathrm{~A}^{3} \Sigma_{u}^{+}, \mathrm{v}=6,7\right.$, and 9) with $\mathrm{O}_{2}, \mathrm{~N}_{2}, \mathrm{CO}_{2}$, Ar, and He, J. Chem. Phys., 101, 7415$7422,1994$.

Lofthus, A. and Krupenie, P. H.: The spectrum of molecular nitrogen, J. Phys. Chem. Ref. Data, 6, 113-307, 1997.

Morozov, I. I. and Temchin, S. M.: Reaction kinetics of singlet oxygen in gas phase, Chem. Plasma, 16, 39-67, 1990 (in Russian).

Morrill, J. and Benesch, W.: Auroral $\mathrm{N}_{2}$ emissions and the effect of collisional processes on $\mathrm{N}_{2}$ triplet state vibrational populations, J. Geophys. Res. 101, 261-274, 1996.

Nahorny, J., Ferreira, C. M., Gordiets, B., Pagnon, D., Touzeau, M., and Vialle, M.: Experimental and theoretical investigation of a $\mathrm{N}_{2}-\mathrm{O}_{2}$ DC flowing glow discharge, J. Phys. D, 28, 738-747, 1995.

Nakamura, H.: Semiclassical approach to charge-transfer processes in ion-molecule collisions, Adv. Chem. Phys., 82(2), 243-319, 1992.

Pejakovic, D. A., Copeland, R. A., Cosby, P. C., and Slanger, T. G.: Studies on the production of $\mathrm{O}_{2}\left(a^{1} \Delta_{g}, v=0\right)$ and $\mathrm{O}_{2}\left(b^{1} \Sigma_{g}^{+}\right.$, $v=0$ ) from collisional removal of $\mathrm{O}_{2}\left(\mathrm{~A}^{3} \Sigma_{u}^{+}, v /=6-10\right)$, J. Geophys. Res., 112, A10307, doi:10.1029/2007JA012520, 2007.
Ricard, A., Moisan, M., and Moreau, S.: Determination, through titration with $\mathrm{NO}$, of the concentration of oxygen atoms in the flowing afterglow of $\mathrm{Ar}-\mathrm{O}_{2}$ and $\mathrm{N}_{2}-\mathrm{O}_{2}$ plasmas used for sterilization purposes, J. Phys. D, 34, 1203-1212, 2001.

Schulz, G. J. and Dowell, J. T.: Excitation of vibrational and electronic levels in $\mathrm{O}_{2}$ by electron impact, Phys. Rev., 128, 174-177, 1962.

Sergienko, T. I. and Ivanov, V. E.: A new approach to calculate the excitation of atmospheric gases by auroral electron impact, Ann. Geophys., 11, 717-727, 1993.

Shyn, T. W. and Sweeney, C. J.: Measurement of absolute differential excitation cross sections of molecular oxygen by electron impact: decomposition of the Herzberg pseudocontinuum, Phys. Rev. A, 62, 022711, doi:10.1103/PhysRevA.62.022711, 2000.

Slanger, T. G. and Huestis, D. L.: $\mathrm{O}_{2}\left(\mathrm{c}^{1} \Sigma_{u}^{-} \rightarrow \mathrm{X}^{3} \Sigma_{g}^{-}\right)$emission in the terrestrial nightglow, J. Geophys. Res., 86, 3551-3554, 1981.

Slanger, T. G., Bischel, W. K., and Dyer, M. J.: Photoexcitation of $\mathrm{O}_{2}$ at $249.3 \mathrm{~nm}$, Chem. Phys. Lett., 108, 472-474, 1984.

Slater, J. C.: Electronic structure of molecules, McGraw-Hill Book Company, New York, 1963.

Swider, W.: Atmospheric formation of NO from $\mathrm{N}_{2}\left(\mathrm{~A}^{3} \Sigma\right)$, Geophys. Res. Lett., 3, 335-337, 1976.

Thomas, J. M. and Kaufman, F.: Rate constants of the reactions of metastable $\mathrm{N}_{2}\left(\mathrm{~A}^{3} \Sigma_{u}^{+}\right)$in $v=0,1,2$, and 3 with groung state $\mathrm{O}_{2}$ and O, J. Chem. Phys., 83, 2900-2903, 1985.

Umemoto, H., Oku, M., and Iwai, T.: Collisional intersystem crossing of $\mathrm{N}_{2}\left(\mathrm{a}^{\prime 1} \Sigma_{u}^{-}\right)$to produce triplet-state molecular nitrogen, J. Chem. Phys., 118, 10006-10011, 2003.

Vallance Jones, A.: Aurora, Geophys. Astrophys. Monogr., D.Reidel, Dordrecht, Netherlands, 1974

Wakiya, K.: Differential and integral cross sections for the electron impact excitation of $\mathrm{O}_{2}$. II. Optically forbidden transitions from the ground state, J. Phys. B, 11, 3931-3938, 1978.

Wouters, E. R., Amaral, G. A., Cone, K. V., Spangler, E. L., Kalogerakis, K. S., and Copeland, R. A.: Temperature dependence of the collisional deactivation processes in excited $\mathrm{O}_{2}$ : A probe to the relaxation pathways and energetics, EOS, Trans AGU, 83, F1106, 2002.

Zhu, C. and Lin, S. H.: Unified semiclassical theory for the twostate system: An analytical solution for general nonadiabatic tunneling, J. Chem. Phys., 125, 044104, doi:10.1063/1.2227399, 2006.

Zipf, E. C.: A laboratory study on the formation of nitrous oxide by the reaction $\mathrm{N}_{2}\left(\mathrm{~A}^{3} \Sigma_{u}^{+}\right)+\mathrm{O}_{2} \rightarrow \mathrm{N}_{2} \mathrm{O}+\mathrm{O}$, Nature, 287, 523-524, 1980 . 